\title{
TYPOLOGIA FORM NACZYŃ KULTURY PUCHARÓW LEJKOWATYCH Z OBSZARU DOLNEGO ŚLĄSKA
}

\author{
TYPOLOGY OF VESSELS FORMS OF THE FUNNEL BEAKER CULTURE \\ FROM LOWER SILESIA
}

The lack of a unified system of description of vessels types of the Funnel Beaker culture in Lower Silesia means that heterogeneous terminology prevents precise classification of ceramic forms found at sites of the culture. The paper presents a proposition of a classification of vessels types of the Funnel Beaker culture developed on the basis of analyses of artefacts from Lower Silesian sites. It has been constructed in a way that enables its complement in case of new discoveries, not falling within the present scope.

KEY WORDS: the Neolithic, the Funnel Beaker culture, typology, Lower Silesia

\section{WSTĘP}

Pomimo wieloletnich badań nad społecznościami kultury pucharów lejkowatych zamieszkującymi w neolicie tereny Dolnego Śląska nie dysponujemy jednolitym systemem opisu typów naczyń tej jednostki kulturowej ${ }^{1}$. Pośrednią tego przyczyną

1 Artykuł ten nie powstałby, gdyby nie życzliwość i pomoc wielu osób. Bardzo dziękuję Profesorowi Bogusławowi Gedidze za udostępnienie do badań materiałów kultury pucharów lejkowatych z osady w Nowej Wsi Wrocławskiej stan. 4, gm. Kąty Wrocławskie oraz Profesorowi Stanisławowi Pazdzie i Profesorowi Włodzimierzowi jest brak podsumowania stanu wiedzy na temat społeczności ,pucharowych” tego regionu w postaci monografii, przy wielu opracowaniach źródłowych (Cholewa 1998; Cholewa, Wojciechowski 2002; Czerniak 2014; Dreczko, Mozgała 2014; Kulczyc-

Wojciechowskiemu, a także Doktorowi Pawłowi Konczewskiemu za możliwość przeglądu materiałów z badanych przez nich stanowisk tej kultury. Praca ta nie byłaby pełna, gdyby nie analiza znalezisk ceramicznych, zarówno publikowanych, jak i niepublikowanych, znajdujących się w zbiorach Muzeum Archeologicznego we Wrocławiu, od- 
ka-Leciejewiczowa 1997, 2001; Kulczycka-Leciejewiczowa, Noworyta 2009; Prus 1975; Romanow 1973; Wojciechowski 1973; Stanisławski, Wojnicka 2014).

Istniejąca $\mathrm{w}$ literaturze przedmiotu niejednorodna terminologia stosowana do określania form naczyń uniemożliwia jednoznaczną klasyfikację morfologiczną ceramiki tej kultury. Największa różnorodność nazewnictwa odnosi się do ceramiki zasobowej. W opracowaniach dolnośląskich stanowisk pojawiają się więc następujące określenia: garnki, naczynia jajowate czy też workowate, odnoszące się do analogicznych kształtem pojemników ceramicznych (np. Cholewa 1998, 126, 129; Romanow 1973, 87-89; Wojciechowski 1973, 3536). Podobny problem dotyczy naczyń szerokootworowych, które w literaturze określane bywają jako czarki, czary, wazy czy też naczynia wazowate (porównaj Cholewa 1998, 136; Romanow 1973, 89; Wojciechowski 1973, 35, 37; Wojciechowski, Cholewa 2000, 84). W mniejszym stopniu dotyczy to opisu przewodnich form, takich jak puchary lejkowate, amfory czy flasze z kryzą.

Uwagę zwraca brak ściśle określonych kryteriów metrycznych oraz stylistycznych, według których można by przyporządkować ceramikę do danej grupy morfologicznej. Doprowadziło to do znacznej dowolności w klasyfikowaniu form ceramicznych znajdowanych na dolnośląskich stanowiskach kultury pucharów lejkowatych (dalej KPL), opartej na subiektywnej ocenie kształtu naczynia. Brak jasnych kryteriów morfologicznych uniemożliwia także jednoznaczne rozróżnienie ta-

dział Muzeum Miejskiego Wrocławia. Serdecznie dziękuję jego pracownikom, szczególnie Magdalenie Szczecińskiej oraz Krzysztofowi Demidziukowi, za pomoc i poświęcony czas. Jestem także niezwykle wdzięczna śp. Doktorowi Jerzemu Romanowowi za udostępnienie do opracowania materiałów kultury pucharów lejkowatych z osad w Gniechowicach stan. 8, gm. Kąty Wrocławskie oraz w Starym Zamku stan. 2 i 7, gm. Sobótka, a także możliwość analiz ceramiki naczyniowej ze stanowiska nr $1 \mathrm{w}$ Tomicach, gm. Jordanów Śląski. Największe podziękowania kieruję do śp. Profesor Anny Kulczyckiej-Leciejewiczowej, która zaszczepiła we mnie pasję do neolitu i zawsze służyła pomocą i radą.

Praca powstała w wyniku realizacji projektu badawczego o nr 2012/05/N/HS3/01423 finansowanego z Narodowego Centrum Nauki. kich form jak misy czy wazy, które pod względem ukształtowania profilu posiadają porównywalne cechy.

W zakresie zaawansowania prac nad zasadami analiz morfologii naczyń Dolny Śląsk odstaje od innych rejonów Polski, gdzie analogiczny problem dotyczący ceramiki KPL naświetlany był już od lat 80. XX w. i doprowadził do wypracowania propozycji klasyfikacji opartych głównie na systemie metrycznym, obiektywizującym identyfikację kształtu naczynia (Jankowska 1980, 31-37, 48-53; Kośko 1981, 23-32, Gumiński 1989, 41n). Pierwszą próbę stworzenia tego rodzaju typologii dla znalezisk dolnośląskich podjęła Anna KulczyckaLeciejewiczowa w monografii osadnictwa neolitycznego ze stanowisk w Strachowie, gm. Kondratowice (1997, 178-185). Zarejestrowanym na osiedlach społeczności KPL dziesięciu głównym formom naczyń Autorka przypisała określone cechy metryczne, bazujące głównie na stosunku wysokości do średnicy wylewu, czy też średnicy wylewu do średnicy brzuśca. Dodatkowo, jako oczywisty, niezbędny czynnik klasyfikujący, podkreśliła w przypadku amfor, kubków i dzbanów obecność uch, a w przypadku flasz z kryzą - kryz. Podtypy danej grupy naczyń określane były na podstawie drugorzędnych cech morfologicznych, takich jak stopień rozchylenia czy forma wylewów, ukształtowanie brzuśców, kształt profilu naczynia czy też w przypadku kubków kształt ucha. Mankamentem zaproponowanej typologii jest niewystarczający opis podtypów form, pozostawiający zbyt duże pole do subiektywnej interpretacji. Co więcej, ze względu na fakt, iż klasyfikacja stworzona została tylko w oparciu o znaleziska ze Strachowa, wiele naczyń KPL z innych dolnośląskich stanowisk tej kultury nie mieści się w jej ramach. Analogiczna typologia wykorzystana została co prawda przy opracowaniu materiałów KPL ze stanowiska nr 6 we Wrocławiu-Partynicach (Kulczycka-Leciejewiczowa 2001, tabela 2), stanowisk nr 4 i 5 w Polwicy oraz nr 8 w Skrzypniku, gm. Domaniów (Kulczycka-Leciejewiczowa, Noworyta 2009, tabela 3, 4), a także nr 15 w Wojkowicach, gm. Źórawina (Stanisławski, Wojnicka 2014, tabela 5), jednakże konieczne było wprowadzenie do niej modyfikacji oraz uzupełnień, czego konsekwencją niestety nie stało się uściślenie warunków, jakie powinny spełniać pojemniki ceramiczne, aby zaklasyfikować je do określonego typu naczynia czy podtypu. 


\section{TYPOLOGIA FORM NACZYŃ}

W celu stworzenia typologii form odpowiadającej realiom dolnośląskiej KPL przeanalizowano morfologię 285 naczyń zachowanych w całości lub w stopniu umożliwiającym odwzorowanie ich pierwotnego kształtu i pozwalającym na przeprowadzenie pomiarów. Pochodziły one $\mathrm{z}$ ponad 60 publikowanych i niepublikowanych stanowisk tej kultury, zarówno osad, cmentarzysk, jak i odkryć przypadkowych dokonanych głównie przed druga wojną światową (tabela 1). Za punkt wyjścia posłużyła zaproponowana przez Aleksandra Kośko (1981, 23-32) klasyfikacja form naczyń KPL z rejonu Kujaw. Naczynia ze stanowisk dolnośląskich wymierzono zgodnie $\mathrm{z}$ zaproponowanym $\mathrm{w}$ niej schematem wskaźników metrycznych (ryc. 1). Uzyskane w ten sposób dane posłużyły do opracowania klasyfikacji naczyń w oparciu o stworzone przez wymienionego wyżej autora grupy typologiczne ceramiki ,pucharowej”. Ze względu na fakt, że liczne analizowane naczynia nie mieściły się w ramach wspomnianej typologii, konieczne stało się wypracowanie nowej, rozbudowanej poprzez dodanie jednostek nadrzędnych oraz rozwinięcie i modyfikację już istniejących. Dla ułatwienia kategoryzacji źródeł uściślono parametry poszczególnych typów morfologicznych tak, aby nie zazębiały się między sobą. Dotyczy to przede wszystkim stosunku wysokości (H1) do średnicy wylewu (R1) naczyń takich jak puchary, misy czy wazy o lejowato ukształtowanym wylewie. Klasyfikację rozszerzono także o jednostki niższego stopnia oparte na relacji wskaźników metrycznych oraz na drugorzędnych cechach mikromorfologicznych (formy wylewów, kształt brzuśca itp.).

Przy tworzeniu typologii brano pod uwagę wspomniane dotychczasowe ustalenia dotyczące form naczyń zaproponowanych dla Strachowa przez A. Kulczycką-Leciejewiczową, jak również klasyfikację materiałów KPL z obszarów sąsiednich, takich jak Górny Śląsk (Bukowska-Gedigowa 1975, 87-122; tabela I-II) i Morawy (Procházková, Šmíd 1999), czy też uściślenia typologii dla wczesnej KPL na Kujawach (Rzepecki 2004, 61-64 - puchar typ E). W przypadku bębnów wzorowano się na systematyce zaproponowanej przez Marzenę Szmyt dla kujawskich materiałów kultury amfor kulistych $(1996,32)$. Uwzględniono w niej również podtypy hipotetyczne, które nie wystapiły dotychczas w zbiorach dolnośląskiej KPL, lecz stanowią bazę wyjściową do klasyfikacji nowych znalezisk.

Ze względu na to, iż opracowana typologia różni się od bazowej klasyfikacji form naczyń A. Kośki dla przejrzystości systematyki każdy typ morfologiczny oznaczono pierwszą literą nazwy, a w przypadku pucharu moździerzowatego oraz amfory jednoczłonowej dwoma pierwszymi literami obu jej członów. Podtypy czy warianty oznaczono kolejnymi liczbami arabskimi, co w konsekwencji prowadzi do oznaczenia naczynia liczbą całkowitą, której długość zależy od szczegółowości opisu formy. Taki zapis umożliwia rozbudowanie typologii w przypadku odkryć naczyń, których forma nie mieści się w przestawionych kryteriach. Ponadto pozwala on, w przypadku niektórych typów morfologicznych, na zastąpienie cyfrą 0 tych informacji dotyczących podtypu czy wariantów z szeregu uściśleń, co do których nie posiadamy danych. Przykładem może być opis bębna ze Strachowa (ryc. 10:13), którego fragmentaryczny stan zachowania, nieznane wartości R1 i H1, nie pozwala na określenie podtypu naczynia, ale umożliwia uściślenie wariantu ze względu na obecność guzów. W tym przypadku naczynie możemy zapisać jako B002, gdzie zera zastępują podtyp oraz odmianę.

\section{Forma:}

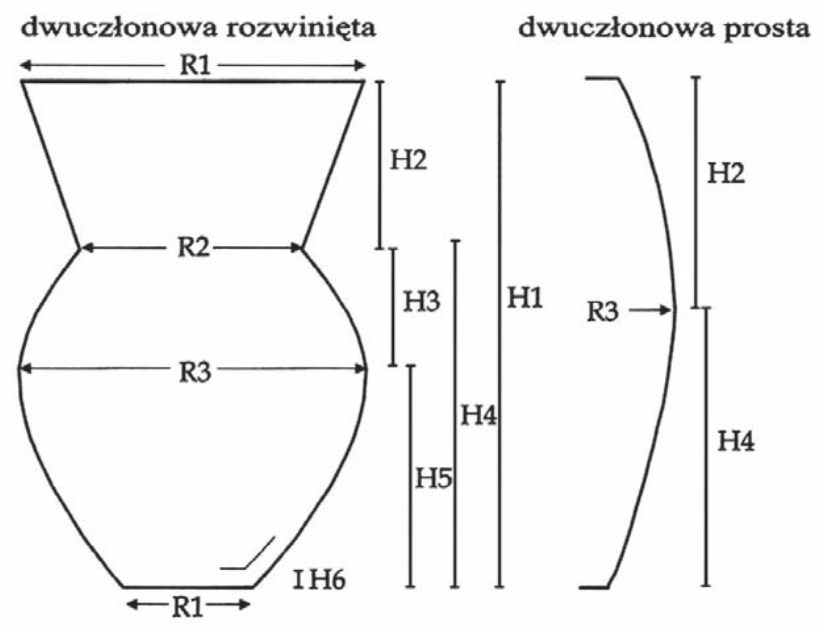

Ryc. 1. Wskaźniki metryczne morfologii naczyń wg Kośko 1981

Fig. 1. Metric indicators of vessels' morphology, after Kośko 1981 


\section{TYPY FORM NACZYŃ}

$\mathrm{P}-$ Puchar lejkowaty = naczynie dwuczłonowe spełniające warunki: 0,8<R1:H1<1,6 i R1 $\geq \mathrm{R} 3$ (ryc. 2);

$\mathrm{P} 1=$ jw., gdy $\mathrm{H} 1: \mathrm{H} 2>4,5$

$\mathrm{P} 11=$ jw., gdy R1:H1<1,1

$\mathrm{P} 111=$ jw., z wyraźnie zaznaczoną profilacją $\mathrm{R} 3: \mathrm{R} 2 \geq 1,1$;

$\mathrm{P} 112=$ jw., z nieznacznie zaznaczoną profilacją $\mathrm{R} 3: \mathrm{R} 2<1,1$ (ryc. 3:3);

$\mathrm{P} 12=$ jw., gdy R1:H1>1,1

$\mathrm{P} 121=$ jw., z wyraźnie zaznaczoną profilacją $\mathrm{R} 3: \mathrm{R} 2 \geq 1,1$;

$\mathrm{P} 122=$ jw., z nieznacznie zaznaczoną profilacją R3:R2<1,1 (ryc. 3:8);

$\mathrm{P} 2=$ jw., gdy $2,5<\mathrm{H} 1: \mathrm{H} 2<4,5$;

$\mathrm{P} 21=$ jw., gdy R1:H1 $\leq 1,05$;

P211 = jw., z wyraźnie zaznaczoną profilacją R3:R2 $\geq 1,1$ (ryc. 3:1, 2);

$\mathrm{P} 212=$ jw., z nieznacznie zaznaczoną profilacją R3:R2<1,1 (ryc. 3:5, 6);

$\mathrm{P} 22=$ jw., gdy $1,05<\mathrm{R} 1: \mathrm{H} 1<1,35$;

P221 = jw., z wyraźnie zaznaczoną profilacją R3:R2 $\geq 1,1$ (ryc. 3:7);

$\mathrm{P} 222$ = jw., z nieznacznie zaznaczoną profilacją R3:R2<1,1 (ryc. 3:4, 9);

$\mathrm{P} 23=$ jw., gdy R1: $\mathrm{H} 1 \geq 1,35$;

$\mathrm{P} 231$ = jw., z wyraźnie zaznaczoną profilacją $R 3: R 2 \geq 1,1$ (ryc. 3:12);

$\mathrm{P} 232$ = jw., z nieznacznie zaznaczoną profilacją R3:R2<1,1 (ryc. 3:10, 11);

P3 = jw., gdy $2,0 \leq \mathrm{H} 1: \mathrm{H} 2<2,5$;

$\mathrm{P} 31=$ jw., gdy R1:H1<1,1;

$\mathrm{P} 311$ = jw., z wyraźnie zaznaczoną profilacją R3:R2 $\geq 1,1$;

$\mathrm{P} 312=\mathrm{jw} ., \mathrm{z}$ nieznacznie zaznaczoną profilacją $\mathrm{R} 3: \mathrm{R} 2<1,1$;

P32 = jw., gdy R1:H1 $\geq 1,1$;

P321 = jw., z wyraźnie zaznaczoną profilacją R3:R2 $\geq 1,1$ (ryc. 3:13);

P322 = jw., z nieznacznie zaznaczoną profilacją R3:R2<1,1 (ryc. 3:14);

P4 = jw., gdy H1:H2<2,0 i 1,0<R1:H1<1,3;

$\mathrm{P} 41=$ jw., $\mathrm{z}$ wyraźnie zaznaczoną profilacją $\mathrm{R} 3: \mathrm{R} 2 \geq 1,1$;

$\mathrm{P} 42=$ jw., z nieznacznie zaznaczoną profilacją $\mathrm{R} 3: \mathrm{R} 2<1,1$;

PM - Puchar moździerzowaty = naczynie jednoczłonowe o prostych ściankach spełniające warunki $0,8<\mathrm{R} 1: \mathrm{H} 1<1,6$ i $\mathrm{R} 1 \geq \mathrm{R} 3$ (ryc. 2 );

PM1 = jw., gdy R1=R3;

$\mathrm{PM} 2=$ jw., gdy R1 $>\mathrm{R} 3$ (ryc. $3: 15,16$ );

$\mathrm{W}-$ waza $=$ naczynie jedno- lub dwuczłonowe, spełniające warunki: 1,6 $<\mathrm{R} 1: \mathrm{H} 1<2$ gdy $\mathrm{R} 1 \geq \mathrm{R} 3$ lub $1,1<\mathrm{R} 1: \mathrm{H} 1<2$ gdy $\mathrm{R} 1<\mathrm{R} 3$ (ryc. 2);

$\mathrm{W} 1=\mathrm{jw} ., \mathrm{o}$ esowatym profilu;

$\mathrm{W} 11=$ jw., gdy $\mathrm{R} 1 \geq \mathrm{R} 3$;

$\mathrm{W} 111=\mathrm{jw} ., \mathrm{z}$ wyraźnie zaznaczoną profilacją $\mathrm{R} 3: \mathrm{R} 2 \geq 1,1$;

$\mathrm{W} 112=\mathrm{jw} ., \mathrm{z}$ nieznacznie zaznaczoną profilacją $\mathrm{R} 3: \mathrm{R} 2<1,1$;

W1111; $1121=$ jw., z wylewem powyżej 1/2 H1 (ryc. 4:2, 6);

W1112; 1122= jw., z wylewem na $1 / 2 \mathrm{H} 1$;

W1113; $1123=$ jw., z wylewem poniżej $1 / 2 \mathrm{H} 1$ (ryc. 4:1, 7);

$\mathrm{W} 12=\mathrm{jw}$. , gdy $\mathrm{R} 1<\mathrm{R} 3$;

$\mathrm{W} 121=\mathrm{jw} ., \mathrm{z}$ wyraźnie zaznaczoną profilacją $\mathrm{R} 3: \mathrm{R} 2 \geq 1,1$;

$\mathrm{W} 122=\mathrm{jw} ., \mathrm{z}$ nieznacznie zaznaczoną profilacją $\mathrm{R} 3: \mathrm{R} 2<1,1$;

W1211; 1221= jw., z wylewem powyżej 1/2 H1 (ryc. 4:5, 10);

W1212; 1222= jw., z wylewem na $1 / 2 \mathrm{H} 1$;

W1213; 1223= jw., z wylewem poniżej $1 \frac{1}{2}$ H1 (ryc. 4:3); 
TYPOLOGIA FORM NACZYŃ KULTURY PUCHARÓW LEJKOWATYCH Z OBSZARU DOLNEGO ŚLĄSKA

W2 = jw., o łamanym profilu (ostrozałomowe);

W21 = jw., z ,wygiętym do środka” (,wyodrębnionym”) barkiem i łukowato wygiętym wylewem: $\mathrm{R} 3>\mathrm{R} 2<\mathrm{R} 1$;

W211 = jw., gdy R1>R3;

$\mathrm{W} 212$ = jw., gdy R1<R3;

W2111; 2121= jw., z wylewem powyżej 1/2 H1 (ryc. 4:4, 8);

W2112; 2122=jw., z wylewem na $1 / 2 \mathrm{H} 1$;

W2113; $2123=$ jw., z wylewem poniżej $1 / 2$ H1 (ryc. 4:9);

$\mathrm{W} 22$ = jw., z ,wygiętym do środka” (,wyodrębnionym”) barkiem R1<R3;

$\mathrm{W} 221=\mathrm{jw}$., z cylindrycznym wylewem $\mathrm{R} 3>\mathrm{R} 2=\mathrm{R} 1$;

$\mathrm{W} 222=$ jw., nieznacznie rozchylonym wylewem R3 $>\mathrm{R} 2<\mathrm{R} 1$ (ryc. 4:12);

W2211; 2221= jw., z załomem brzuśca powyżej $2 /{ }_{3} \mathrm{H} 1$;

W2212; 2222= jw., z załomem brzuśca na ${ }_{3}{ }_{3} \mathrm{H} 1$ (ryc. 4:15);

W2213; 2223=jw., z załomem brzuśca poniżej ${ }^{2} / 3$ H1 (ryc. 4:11);

W23 = jw., z „niewyodrębnionym barkiem” (jednoczłonowa);

$\mathrm{W} 231$ = jw., ze stożkowatym wylewem R3 $>\mathrm{R} 1$;

$\mathrm{W} 232=\mathrm{jw} ., \mathrm{z}$ cylindrycznym wylewem $\mathrm{R} 3=\mathrm{R} 1$;

W2311; 2321= jw., z załomem brzuśca powyżej $2 / 3$ H1 (ryc. 4:14, 16, 18);

W2312; 2322= jw., z załomem brzuśca na $2 / 3 \mathrm{H} 1$;

W2313; 2323= jw., z załomem brzuśca poniżej ${ }^{2 /}{ }_{3} \mathrm{H1}$;

$\mathrm{W} 3$ = jw., o łukowatym profilu;

$\mathrm{W} 31=$ jw., z cylindrycznym wylewem;

$\mathrm{W} 311=$ jw., $\mathrm{z}$ wyodrębnionym wylewem $\mathrm{R} 2=\mathrm{R} 1$;

$\mathrm{W} 312=$ jw., $\mathrm{z}$ niewyodrębnionym wylewem (jednoczłonowa);

W3111; 3121 = jw., z załomem brzuśca powyżej 1/2 H1 (ryc. 4:20);

W3112; $3122=$ jw., z załomem brzuśca na $1 / 2 \mathrm{H} 1$;

$\mathrm{W} 3113 ; 3123=\mathrm{jw} ., \mathrm{z}$ załomem brzuśca poniżej $1 \frac{1}{2} \mathrm{H} 1$;

$\mathrm{W} 32=$ jw., $\mathrm{z}$ wylewem zagiętym do środka (jednoczłonowa) (ryc. 4:17);

$\mathrm{W} 321=\mathrm{jw}$., z załomem brzuśca powyżej $1 / 2 \mathrm{H} 1$;

$\mathrm{W} 322=\mathrm{jw} ., \mathrm{z}$ załomem brzuśca na $1 / 2 \mathrm{H} 1$;

$\mathrm{W} 323$ = jw., z załomem brzuśca poniżej $1 / 2 \mathrm{H} 1$;

$\mathrm{W} 33$ = jw., $\mathrm{z}$ wylewem lejkowatym $\mathrm{R} 2<\mathrm{R} 1$;

W331= jw., z załomem brzuśca powyżej 1/2 H1 (ryc. 4:19);

$\mathrm{W} 332$ = jw., z załomem brzuśca na $1 \frac{1}{2} \mathrm{H} 1$;

$\mathrm{W} 333$ = jw., z załomem brzuśca poniżej $1 / 2 \mathrm{H} 1$;

$\mathrm{W} 4=$ jw., o prostym profilu (jednoczłonowa) (ryc. 4:21);

$\mathrm{M}$ - Misa = naczynie jedno- lub dwuczłonowe, spełniające warunki: R1:H1 22,00 i R1:R2 $\geq 0,90$ (ryc. 2);

M1 = jw., o esowatym profilu;

M11 = jw., gdy R1>R3;

M111 = jw., z wyraźnie zaznaczoną profilacją $\mathrm{R} 3: \mathrm{R} 2 \geq 1,1$;

M112 = jw., z nieznacznie zaznaczoną profilacją R3:R2<1,1 (ryc. 5:1);

M1111; 1121 = jw., $\mathrm{z}$ wylewem powyżej $1 / 2 \mathrm{H} 1$;

M1112; 1122 = jw., z wylewem na $1 / 2 \mathrm{H} 1$;

M1113; $1123=$ jw., z wylewem poniżej $1 / 2 \mathrm{H} 1$;

$\mathrm{M} 12$ = jw., gdy R1 $\leq \mathrm{R} 3$;

$\mathrm{M} 121=\mathrm{jw} ., \mathrm{z}$ wyraźnie zaznaczoną profilacją $\mathrm{R} 3: \mathrm{R} 2 \geq 1,1 ;$

M122 = jw., z nieznacznie zaznaczoną profilacją R3:R2<1,1 (ryc. 5:2);

M1211; 1221= jw., z wylewem powyżej 1/2 H1 (ryc. 5:13);

M1212; 1222= jw., $\mathrm{z}$ wylewem na $1 / 2 \mathrm{H} 1$;

M1213; 1223=jw., z wylewem poniżej 1/2 H1; 

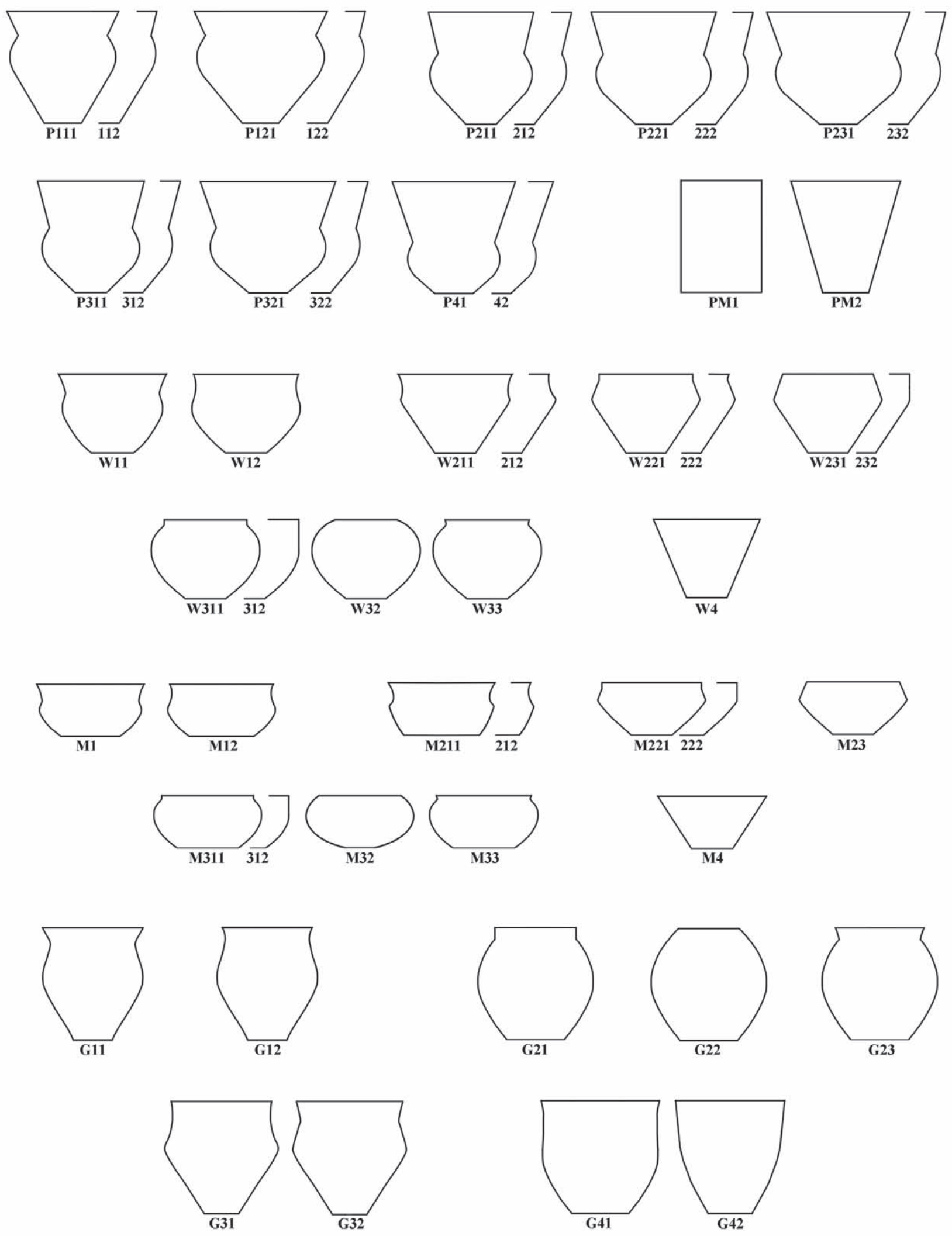

Ryc. 2. Typologia pucharów lejkowatych, moździerzowatych, waz, mis oraz garnków kultury pucharów lejkowatych. Rys. E. Dreczko

Fig. 2. Typology of funnel beakers, mortar beakers, vases bowls and pots of the Funnel Beaker culture. Drawn by E. Dreczko 


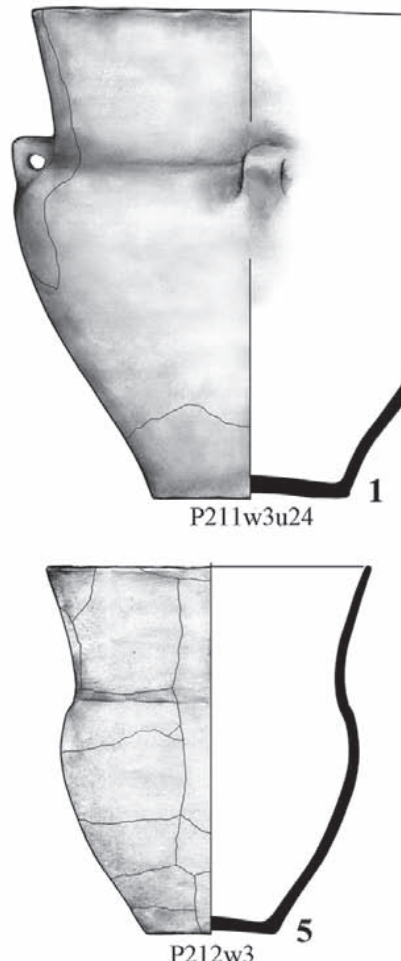

P212w3

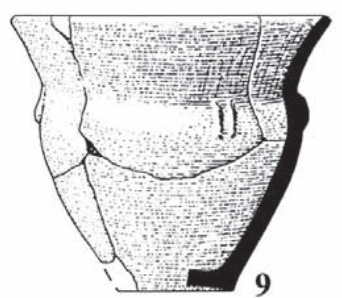

$\mathrm{P} 222 \mathrm{w} 4$
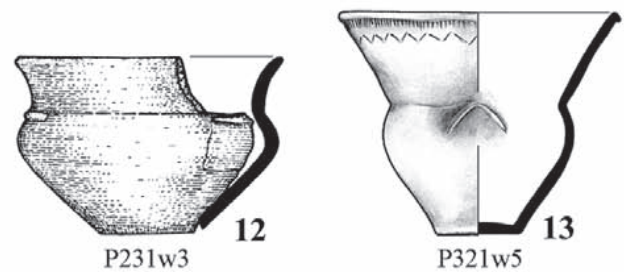
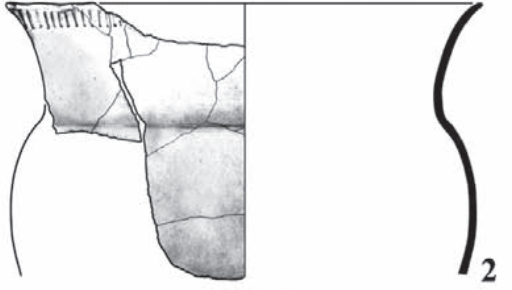

P211w3

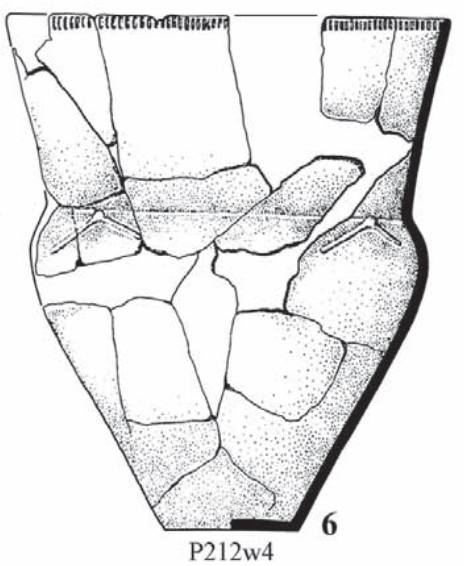

0 $10 \mathrm{~cm}$
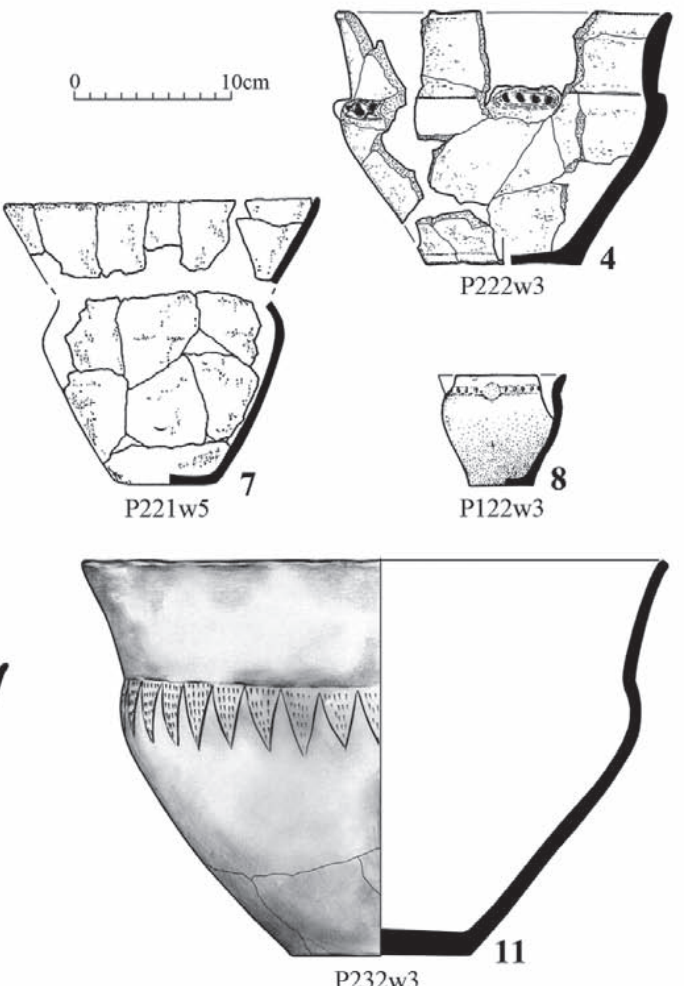

P232w3
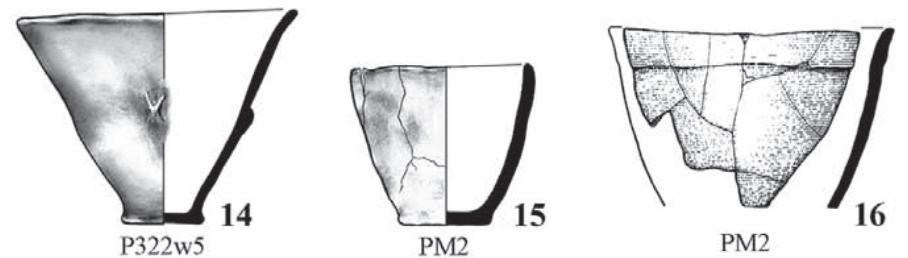

Ryc. 3. Puchary lejkowate (1-14) i moździerzowate (15-16) z dolnośląskich stanowisk kultury pucharów lejkowatych. 1 - Kojęcin Jaksonów stan. 1, gm. Borów; 2 - Jankowice stan. 3, gm. Oława; 3, 6 - Strachów stan. 2, gm. Kondratowice; 4 - Nowa Wieś Wrocławska stan 4, gm. Katy Wrocławskie; 5, 13 - Jordanów Śląski stan. 5; 7 - Wrocław-Partynice stan. 6; 8 - Wilkowice stan. 8, gm. Żórawina; 9 - Zarzyca stan. 2, gm. Kondratowice; 10 - Stary Zamek stan. 7 , gm. Jordanów Śląski; 11, 15 - Gniechowice stan. 8, gm. Kąty Wrocławskie; 12, 16 - Janówek stan. 1,

gm. Jordanów Śląski; 14 - Trzebnik stan. 11 gm. Łagiewniki. Rys. N. Lenkow: 3, 6 - wg A. Kulczycka-Leciejewiczowa 1997, ryc. 86:15; 88:35; 4 - wg Dreczko w druku; 7 - wg A. Kulczycka-Leciejewiczowa 2001, ryc. 4:8;

8 - K. Kopeć et al. 2001, ryc. 5:6; 9 - wg O. Prus 1977, ryc. 25a; 12, 16 -wg W. Wojciechowski 1973, ryc. 34a, 32h

Fig. 3. Funnel beakers (1-14) and mortar beakers (15-16) from Lower Silesian sites of the Funnel Beaker culture.

1 - Kojęcin Jaksonów site 1, Borów district; 2 - Jankowice site 3, Oława district; 3, 6 - Strachów site 2, Kondratowice district; 4 - Nowa Wieś Wrocławska site 4, Kąty Wrocławskie district; 5, 13 - Jordanów Śląski site 5; 7 - WrocławPartynice site 6; 8 - Wilkowice site 8, Żórawina district; 9 - Zarzyca site 2, Kondratowice district; 10 - Stary Zamek site 7, Jordanów Śląski district; 11, 15 - Gniechowice site 8, Kąty Wrocławskie district; 12, 16 - Janówek site 1, Jordanów Śląski district; 14 - Trzebnik site 11 Łagiewniki district. Drawn by N. Lenkow: 3, 6 - after A. KulczyckaLeciejewiczowa 1997, fig. 86:15; 88:35; 4 - after Dreczko (in press); 7 - after A. Kulczycka-Leciejewiczowa 2001, fig. 4:8; 8 - K. Kopeć et al. 2001, fig. 5:6; 9 - after O. Prus 1977, fig. 25a; 12, 16 - after W. Wojciechowski 


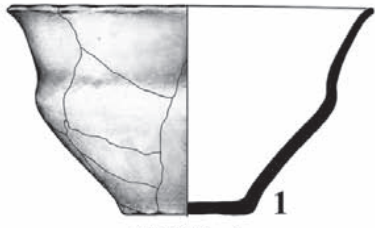

W1123w4

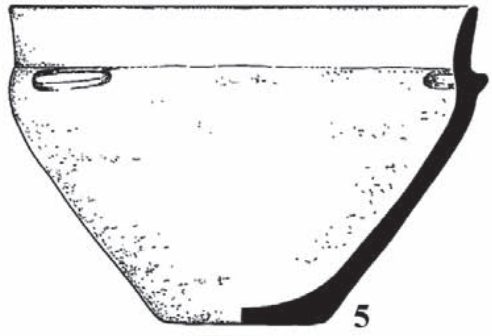

W1221w3

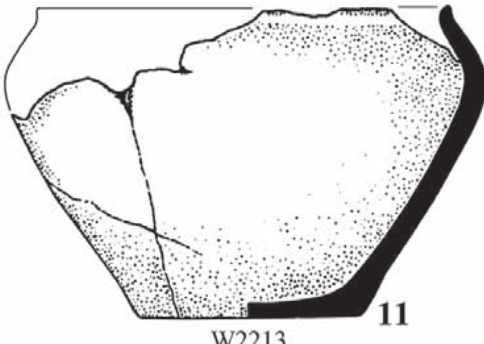

W2213
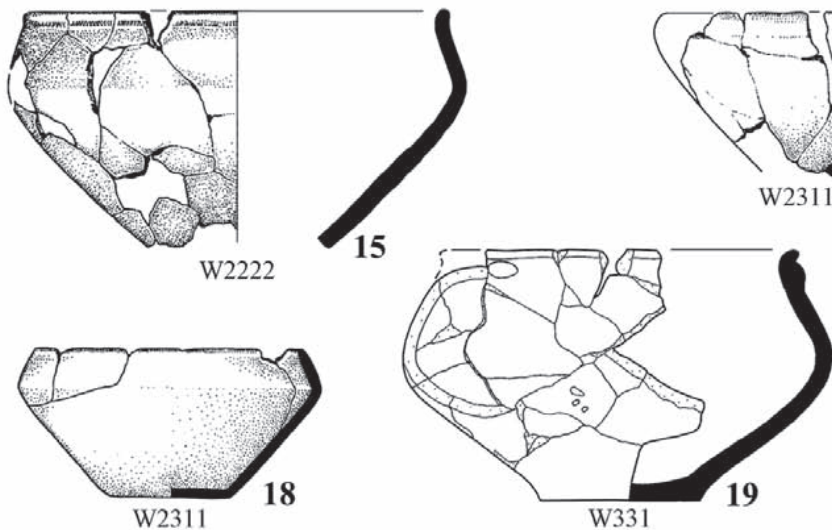

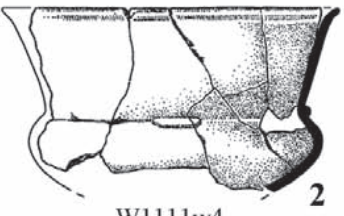

W1111w4 W2113
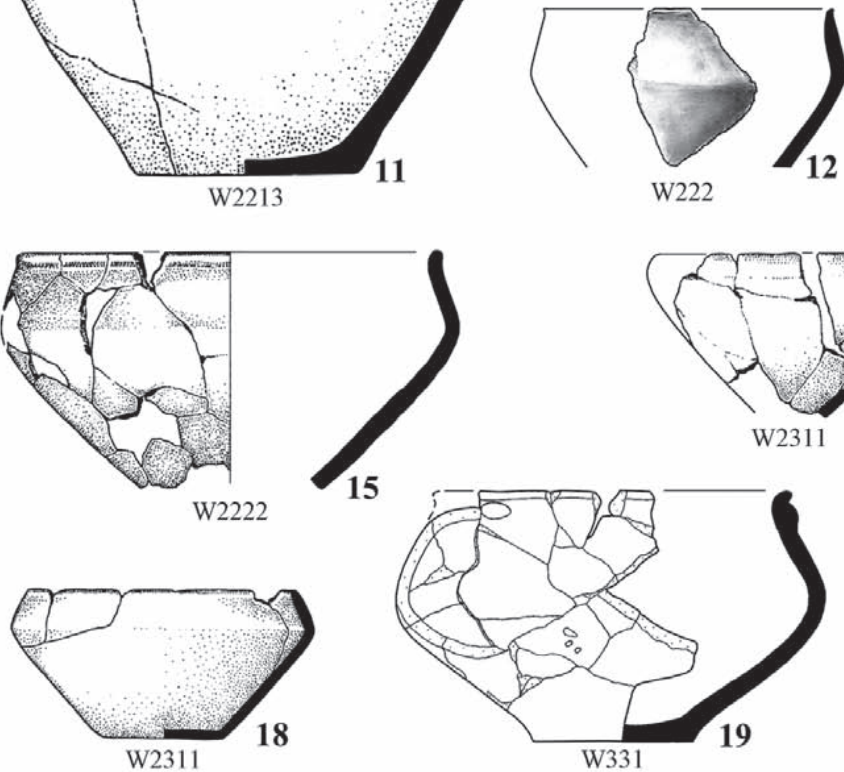

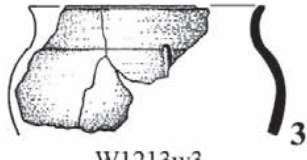

W1213w3

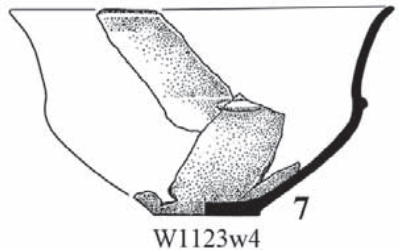

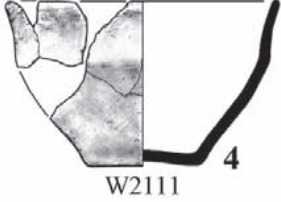

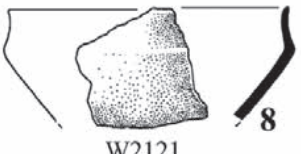

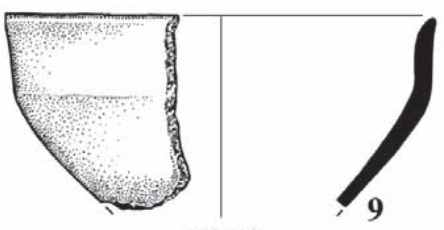

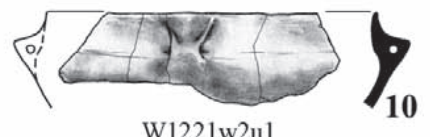

W1221w2ul
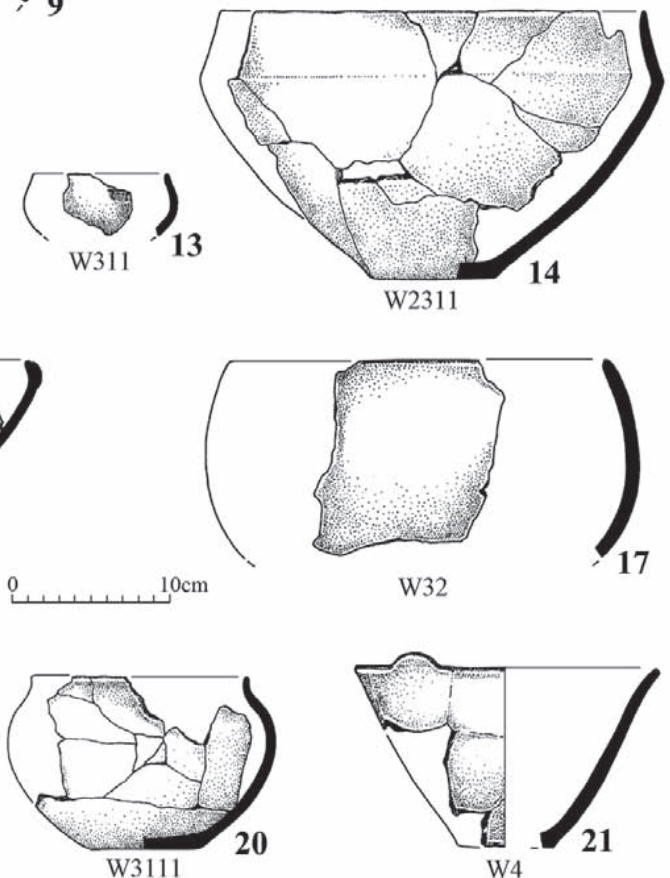

W32

Ryc. 4. Wazy z dolnośląskich stanowisk kultury pucharów lejkowatych.

1, 6 - Wrocław-Partynice stan. 1; 2, 7, 8, 11, 13, 14, 18, 20 - Strachów stan. 2, gm. Kondratowice; 3 - Janówek stan. 1, gm. Sobótka; 4 - Małuszów stan. 10, gm. Kobierzyce; 5 - Nowa Wieś Wrocławska stan 4, gm. Katy Wrocławskie;

9, 15, 17, 21 - Polwica stan. 4, 5 i Skrzypnik stan. 8, gm. Domaniów; 10 - Wilczków stan 2, gm. Żórawina; 12 - Stary

Zamek stan. 7, gm. Sobótka; 16 - Strachów stan. 6, gm. Kondratowice; 19 - Zarzyca stan.6, gm., Kondratowice.

Rys. N. Lenkow: 2, 7, 8, 11, 13, 14, 18, 20 - wg A. Kulczycka-Leciejewiczowa 1997, ryc. 76:4, 21; 78:17, 18, 22; 95:4, 14; 96:32; 101:1; 3 - wg W. Wojciechowski 1973, ryc. 17h; 5 - wg Dreczko w druku; 9, 15, 17,

21 - wg A. Kulczycka-Leciejewiczowa, E. Noworyta 2009, ryc. 20:1; 43:12; 71:1, 12; 19 - wg K. Czarniak 2008, ryc. 8a

Fig. 4. Vases from Lower Silesian sites of the Funnel Beaker culture.

1, 6 - Wrocław-Partynice site 1; 2, 7, 8, 11, 13, 14, 18, 20-Strachów site 2, Kondratowice district; 3 - Janówek site 1,

Sobótka district; 4 - Małuszów site 10, Kobierzyce district; 5 - Nowa Wieś Wrocławska site 4, Kąty Wrocławskie district; 9, 15, 17, 21 - Polwica sites 4, 5 and Skrzypnik site 8, Domaniów district; 10 - Wilczków site 2,

Żórawina district; 12 - Stary Zamek site 7, Sobótka district; 16 - Strachów site 6, Kondratowice district;

19 - Zarzyca site 6, Kondratowice district. Drawn by N. Lenkow: 2, 7, 8, 11, 13, 14, 18, 20 - after A. Kulczycka-

Leciejewiczowa 1997, fig. 76:4, 21; 78:17, 18, 22; 95:4, 14; 96:32; 101:1; 3 - after W. Wojciechowski 1973, fig. 17h; 5 - after Dreczko (in print); 9, 15, 17, 21 - after A. Kulczycka-Leciejewiczowa, E. Noworyta 2009,

fig. 20:1; 43:12; 71:1, 12; 19 - after K. Czarniak 2008, fig. 8a 
M2 = jw., o łamanym profilu (ostrozałomowe);

M21 = jw., z lejowato wyodrębnionym wylewem;

M211 = jw., gdy R1>R3 (ryc. 5:3);

M212 = jw., gdy R1<R3;

M2111; $2121=$ jw., z wylewem powyżej $1 \frac{1}{2}$ H1 (ryc. 5:4)

M2112; $2122=$ jw., z wylewem na $1 / 2 \mathrm{H} 1$;

M2113; 2123 = jw., z wylewem poniżej 1/2 H1;

$\mathrm{M} 22=\mathrm{jw} ., \mathrm{z}$ cylindrycznym wylewem $\mathrm{R} 1=\mathrm{R} 2$;

$\mathrm{M} 221$ = jw., z wyodrębnionym wylewem R2<R3;

M222 = jw., z niewyodrębnionym wylewem (jednoczłonowa) (ryc. 5:5);

M2211; $2221=$ jw., z załomem brzuśca powyżej $1 \frac{1}{2} \mathrm{H1}$;

M2212; $2222=$ jw., z załomem brzuśca na $1 / 2 \mathrm{H} 1$;

M23 = jw., $\mathrm{z}$ wylewem zagiętym do środka $\mathrm{R} 1<\mathrm{R} 2$;

M231 = jw., z załomem brzuśca powyżej 1/2 H1 (ryc. 5:11);

M232 = jw., z załomem brzuśca na $1 / 2 \mathrm{H} 1$;

M233 = jw., z załomem brzuśca poniżej ${ }^{1 / 2} \mathrm{H} 1$;

M3 = jw., o łukowatym profilu;

M31 = jw., z cylindrycznym wylewem;

M311 = jw., z wyodrębnionym wylewem R2=R1 (ryc. 5:8);

M312= jw., z niewyodrębnionym wylewem (jednoczłonowa);

M3111; M3121 = jw., z załomem brzuśca powyżej wysokości 1/2 H1;

M3112; M3122 = jw., z załomem brzuśca na wysokości 1/2 H1;

M3113; M3123 = jw., z załomem brzuśca poniżej wysokości 1/2 H1;

M32 = jw., z wylewem zagiętym do środka (jednoczłonowa) (ryc. 5:6);

M321 = jw., z załomem brzuśca powyżej wysokości $1 \frac{1}{2} \mathrm{H} 1$;

M322 = jw., z załomem brzuśca na wysokości $1 \frac{1}{2} \mathrm{H} 1$;

M323 = jw., z załomem brzuśca poniżej wysokości $1 / 2 \mathrm{H} 1$;

$\mathrm{M} 33$ = jw., z wylewem lejowatym R2<R1 (ryc. 5:7);

M331 = jw., z załomem brzuśca powyżej wysokości 1/2 H1;

M332 = jw., z załomem brzuśca na wysokości $1 \frac{1}{2} \mathrm{H} 1$;

M333 = jw., z załomem brzuśca poniżej wysokości $1 \frac{1}{2} \mathrm{H} 1$;

M4 = jw., o prostym profilu (jednoczłonowa) (ryc. 5:9, 10, 12);

$\mathrm{G}-$ Garnek = naczynie jedno- lub dwuczłonowe, spełniające warunki: R1:H1 $\leq 1,1$ (ryc. 2);

$\mathrm{G} 1=$ jw., o esowatym profilu: $\mathrm{R} 2<\mathrm{R} 1, \mathrm{R} 3$;

$\mathrm{G} 11=$ jw., gdy R3=R1;

G111 = jw., gdy R1:H1<0,7 (,wysmukłe”);

G112= jw., gdy 0,7 $\leq \mathrm{R} 1: \mathrm{H} 1<1,4$ (,,przysadziste”) (ryc. 6:1);

G12 = jw., gdy R3>R1;

G121 = jw., gdy R1:H1<0,7 (,wysmukłe");

G122= jw., gdy 0,7 $\leq \mathrm{R} 1: \mathrm{H} 1<1,1$ (,przysadziste”) (ryc. 6:3);

$\mathrm{G} 2=$ jw., o łukowatym profilu;

$\mathrm{G} 21=$ jw., z cylindrycznym wylewem gdy R2=R1 (ryc. 6:4);

G22 = jw., z wylewem zagiętym do środka (jednoczłonowy) (ryc. 6:9);

$\mathrm{G} 23$ = jw., z wylewem lejkowatym gdy R2 $\leq \mathrm{R} 1$ (ryc. 6:2);

$\mathrm{G} 3$ = jw., o łamanym profilu (ostrozałomowe);

$\mathrm{G} 31$ = jw., z łukowato wygiętym wylewem (ryc. 6:5);

$\mathrm{G} 32$ = jw., $\mathrm{z}$ wylewem lejkowatym (ryc. 6:7);

$\mathrm{G} 4=$ jw., kielichowate $\mathrm{R} 1 \geq \mathrm{R} 2$ i $0,95<\mathrm{R} 3: \mathrm{R} 2<1,1$;

G41= jw., gdy R3 $>$ R2 (ryc. 6:6, 10);

$\mathrm{G} 42=$ jw., gdy $\mathrm{R} 3 \leq \mathrm{R} 2<\mathrm{R} 1$ (ryc. $6: 8$ ); 


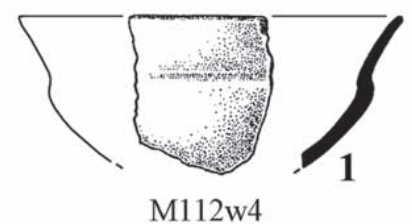

M112w4

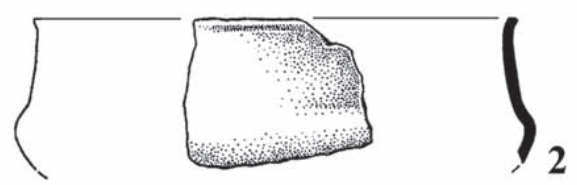

M122w2

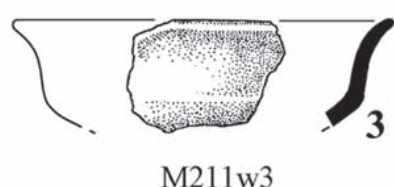

M211w3

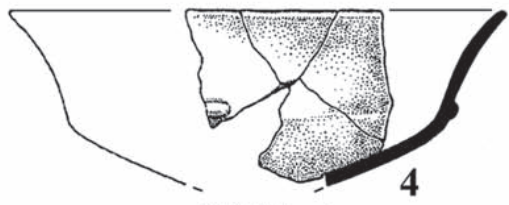

M2111w4

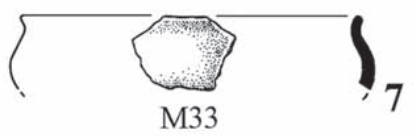

M33

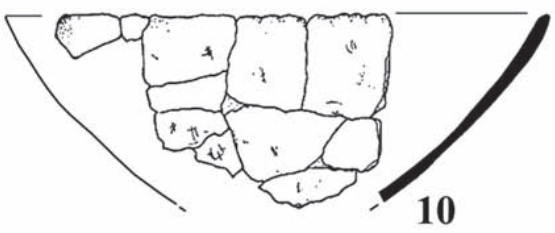

M4

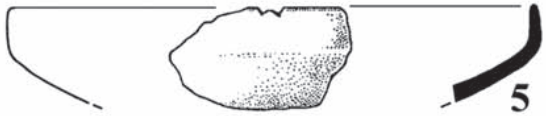

M222

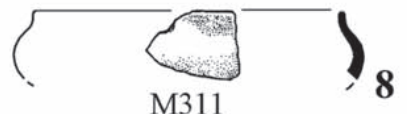

눈. $10 \mathrm{~cm}$
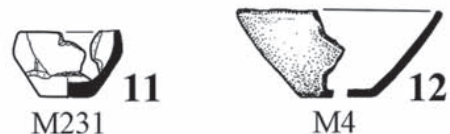

M4

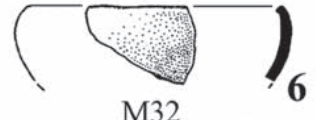

M32

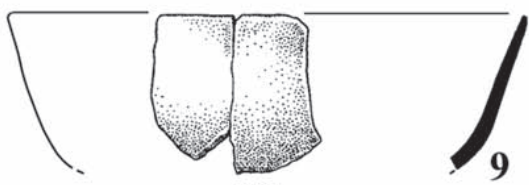

M4

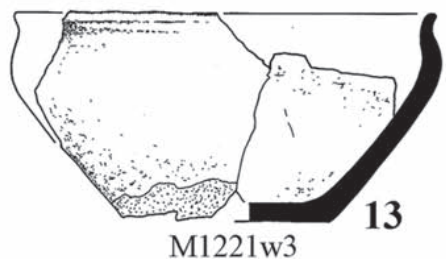

Ryc. 5. Misy z dolnośląskich stanowisk kultury pucharów lejkowatych.

1-9 - Strachów stan. 2, gm. Kondratowice; 10 - Wrocław-Partynice stan. 6; 11 - Zarzyca stan. 6, gm. Kondratowice; 12 - Polwica stan. 4, 5 i Skrzypnik stan. 8, gm. Domaniów; 13 - Nowa Wieś Wrocławska stan 4, gm. Kąty Wrocławskie. Rys. N. Lenkow: 1-9 - wg A. Kulczycka-Leciejewiczowa 1997, ryc. 70:27; 76:10; 78:2, 20, 21; 82:39;

10 - wg A. Kulczycka-Leciejewiczowa 2001, ryc. 8:13; 11 - wg K. Czerniak 2008, ryc. 7e; 12 - wg A. KulczyckaLeciejewiczowa, E. Noworyta 2009, ryc. 71:11; 13 - wg Dreczko w druku

Fig. 5. Bowls from Lower Silesian sites of the Funnel Beaker culture.

1-9 - Strachów site 2, Kondratowice district; 10 - Wrocław-Partynice site 6;11 - Zarzyca site 6,

Kondratowice district; 12 - Polwica sites 4, 5 and Skrzypnik site. 8, Domaniów district; 13 - Nowa Wieś Wrocławska site 4, Kąty Wrocławskie district. Drawn by N. Lenkow: 1-9 - after A. Kulczycka-Leciejewiczowa 1997, fig. 70:27; 76:10; 78:2, 20, 21; 82:39; 10 - after A. Kulczycka-Leciejewiczowa 2001, fig. 8:13; 11 - after K. Czerniak 2008, fig. 7e; 12 - after A. Kulczycka-Leciejewiczowa, E. Noworyta 2009, fig. 71:11; 13 - after Dreczko (in press) 


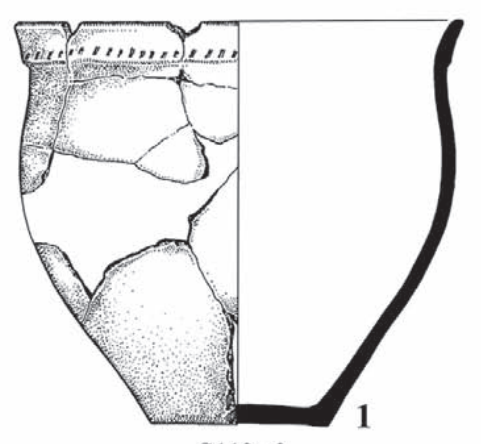

G112w3

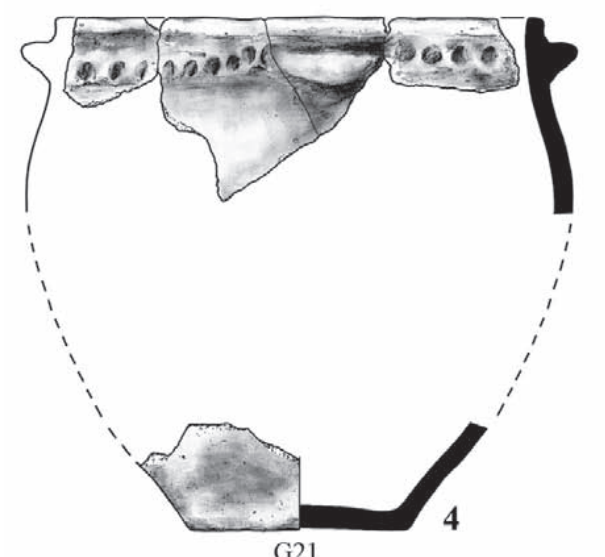

G21

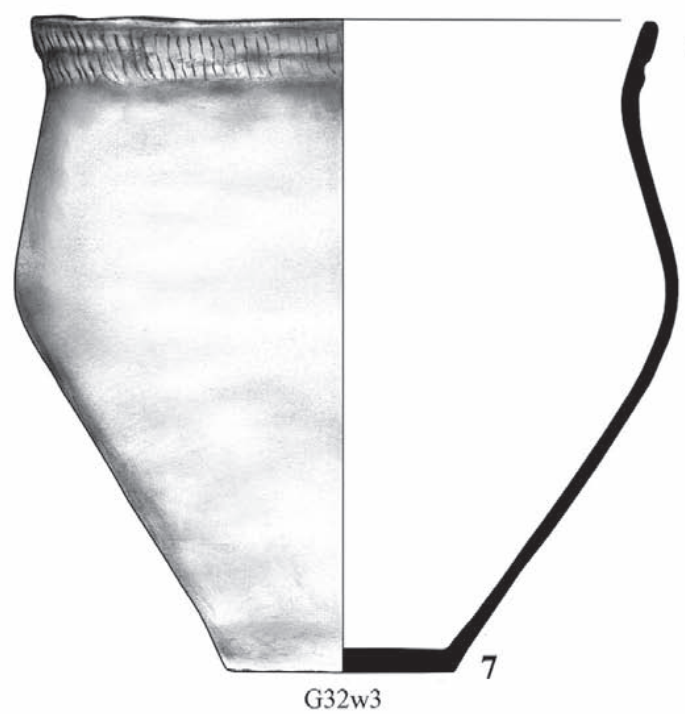

G32w3
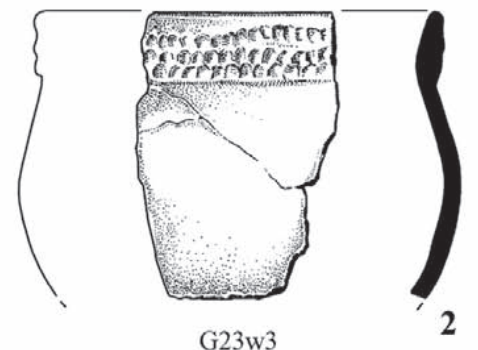

$10 \mathrm{~cm}$

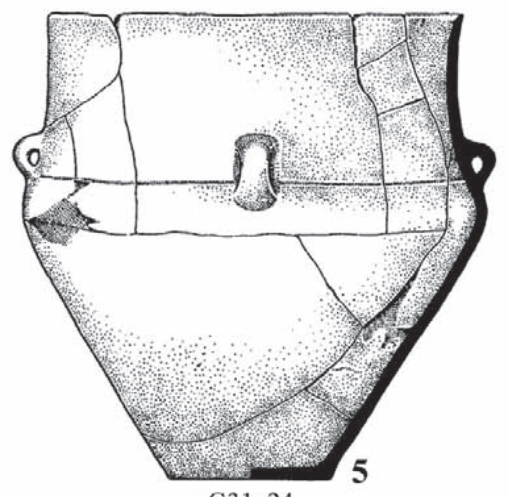

G31u24

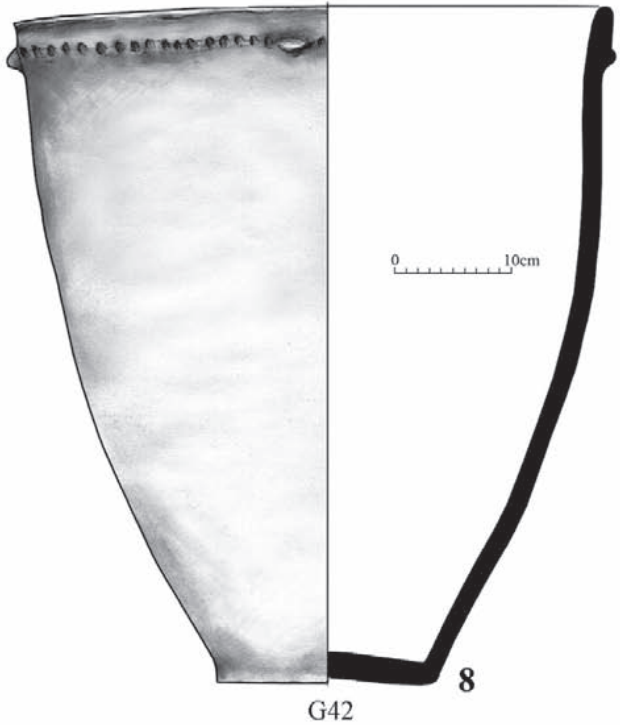

G42

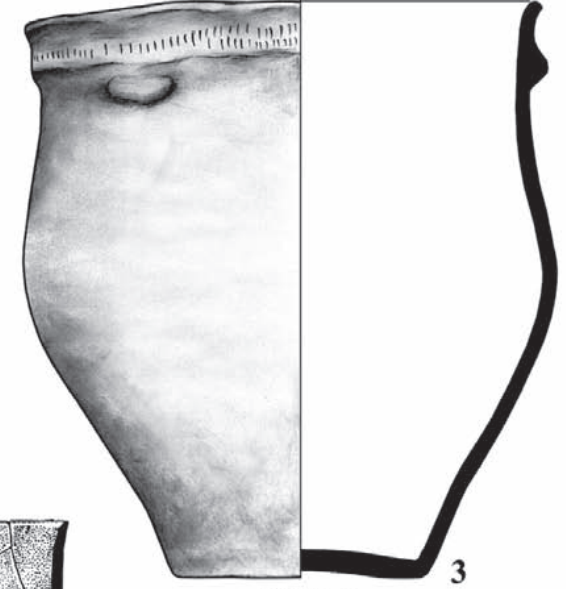

G122w3

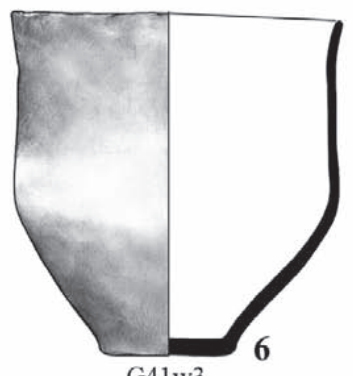

G41w3

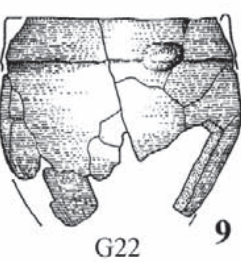

G22

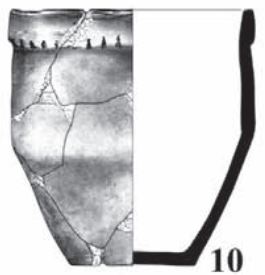

G41

Ryc. 6. Garnki z dolnośląskich stanowisk kultury pucharów lejkowatych.

1, 2 - Polwica stan. 4, 5 i Skrzypnik stan. 8, gm. Domaniów; 3, 7 - Kilianów, gm. Kąty Wrocławskie; 4 - Małuszów stan. 10, gm. Kobierzyce; 5 - Strachów stan. 2, gm. Kondratowice; 6 - Wrocław- ul. Sztabowa; 8 - Trzebnik stan. 10, gm. Łagiewniki; 9 - Janówek stan. 1, gm. Jordanów Śląski; 10 - Stary Zamek stan. 7, gm. Sobótka.

Rys. N. Lenkow: 1, 2 - wg A. Kulczycka-Leciejewiczowa, E. Noworyta 2009, ryc. 49:9; 71:7; 5 - wg A. KulczyckaLeciejewiczowa 1997, ryc. 84:3; 9 - wg W. Wojciechowski 1973, ryc. 20a;

Fig. 6. Pots from Lower Silesian sites of the Funnel Beaker culture.

1, 2 - Polwica sites 4, 5 and Skrzypnik site 8, Domaniów district; 3, 7 - Kilianów, Kąty Wrocławskie district; 4 - Małuszów site 10, Kobierzyce district; 5 - Strachów site 2, Kondratowice district; 6 - Wrocław- ul. Sztabowa; 8 - Trzebnik site 10, Łagiewniki district; 9 - Janówek site 1, Jordanów Śląski district; 10 - Stary Zamek site 7, Sobótka district. Drawn by N. Lenkow: 1, 2 - after A. Kulczycka-Leciejewiczowa, E. Noworyta 2009, fig. 49:9; 71:7; 5 - after A. Kulczycka-Leciejewiczowa 1997, fig. 84:3; 9 - after W. Wojciechowski 1973, fig. 20a 
A - Amfora = naczynie dwuczłonowe o symetrycznie rozlokowanych uchach (lub innych uchwytach, np. guzkach), spełniające warunki: R3>R1, R3> R2 oraz R3:R2>1,3 (ryc. 7);

$\mathrm{A} 1=$ jw., o symetrycznym brzuścu: $0,90 \leq \mathrm{H} 3: \mathrm{H} 5<1,00$;

$\mathrm{A} 11=$ jw. o łukowato wygiętym brzuścu (ryc. 81 );

A12 = jw. o łamanym brzuścu (ostrozałomowe) (ryc. 8:2);

$\mathrm{A} 2$ = jw., o lekko podkreślonej mikromorfologicznie asymetrii brzuśca: 0,60 $\leq \mathrm{H} 3: \mathrm{H} 5<0,9$;

A21 = jw., o łukowato wygiętym brzuścu (ryc. 8:9, 10);

A22 = jw., jw. o łamanym brzuścu (ostrozałomowe) (ryc. 8:6-8);

A3 = jw., o wyraziście podkreślonej mikromorfologicznie asymetrii brzuśca: H3:H5<0,60;

$\mathrm{A} 31$ = jw., o łukowato wygiętym brzuścu (ryc. 8:3, 4, 12);

$\mathrm{A} 32=\mathrm{jw}$. jw. o łamanym brzuścu (ostrozałomowe) (ryc. 8:11);

A4 = jw., o wyraziście podkreślonej mikromorfologicznie asymetrii brzuśca: $\mathrm{H} 5<\mathrm{H} 3$;

A41 = jw., o łukowato wygiętym brzuścu;

A42 = jw., jw. o łamanym brzuścu (ostrozałomowe) (ryc. 8:13);

AJ - Amfora jednoczłonowa = naczynie jednoczłonowe (dwuczłonowe proste) bezuche lub o symetrycznie rozlokowanych uchach (lub innych uchwytach, np. guzkach), spełniające warunki metryczne amfor (tzw. amfora lubońska) (ryc. 7);

$\mathrm{AJ} 1=$ jw., z wyraźnie zaznaczoną profilacją: R3:R2 $\geq 1,1$ (ryc. 8:5);

$\mathrm{AJ} 2=\mathrm{jw} ., \mathrm{z}$ nieznacznie zaznaczoną profilacją:u R3:R2<1,1;

$\mathrm{D}-$ Dzban = naczynie dwuczłonowe o asymetrii poziomej $\mathrm{w}$ rozmieszczeniu uch, spełniające warunki: R3 $>$ R1 i R1:H1<1 (ryc. 7);

$\mathrm{D} 1=\mathrm{jw}$., o symetrycznym brzuścu: $0,90 \leq \mathrm{H} 3: \mathrm{H} 5<1,00$;

D11= jw. o łukowato wygiętym brzuścu;

D12 = jw. o łamanym brzuścu (ostrozałomowe);

D111; $121=$ jw., z uchem powyżej krawędzi wylewu (ryc. 9:1);

D112; 122 = jw. z uchem na wysokości krawędzi wylewu;

D113; 123 = jw. $z$ uchem poniżej krawędzi wylewu;

D114; 124 - jw., z uchem przy załomie wylewu i brzuśca;

D2 = jw., o lekko podkreślonej mikromorfologicznie asymetrii brzuśca: $0,60 \leq \mathrm{H} 3: \mathrm{H} 5<0,9$;

D21 = jw., o łukowato wygiętym brzuścu;

D22 = jw., jw. o łamanym brzuścu (ostrozałomowe);

D211; 221 = jw., z uchem powyżej krawędzi wylewu (ryc. 9:7);

D212; 222 = jw., z uchem na wysokości krawędzi wylewu (ryc. 9:2);

D213; $223=$ jw., z uchem poniżej krawędzi wylewu (ryc. 9:6);

D214; 224 - jw., z uchem przy załomie wylewu i brzuśca;

D3 = jw., o wyraziście podkreślonej mikromorfologicznie asymetrii brzuśca: H3:H5<0,60;

D31 = jw., o łukowato wygiętym brzuścu;

D32 = jw., jw. o łamanym brzuścu (ostrozałomowe);

D311; 321 = jw., z uchem powyżej krawędzi wylewu;

D312; 322 = jw. z uchem na wysokości krawędzi wylewu;

D313; $323=$ jw., z uchem poniżej krawędzi wylewu (ryc. 9:3);

D314; 324 - jw., z uchem przy załomie wylewu i brzuśca (ryc. 9:4);

D4 = jw., o wyraziście podkreślonej mikromorfologicznie asymetrii brzuśca, gdy H5>H3;

D41 = jw., o łukowato wygiętym brzuścu;

D42 = jw., jw. o łamanym brzuścu (ostrozałomowe);

D411; 421 = jw., z uchem powyżej krawędzi wylewu (ryc. 9:8);

D412; 422 = jw. z uchem na wysokości krawędzi wylewu;

D413; 423 = jw. $\mathrm{z}$ uchem poniżej krawędzi wylewu;

D414; 424 - jw., z uchem przy załomie wylewu i brzuśca; 

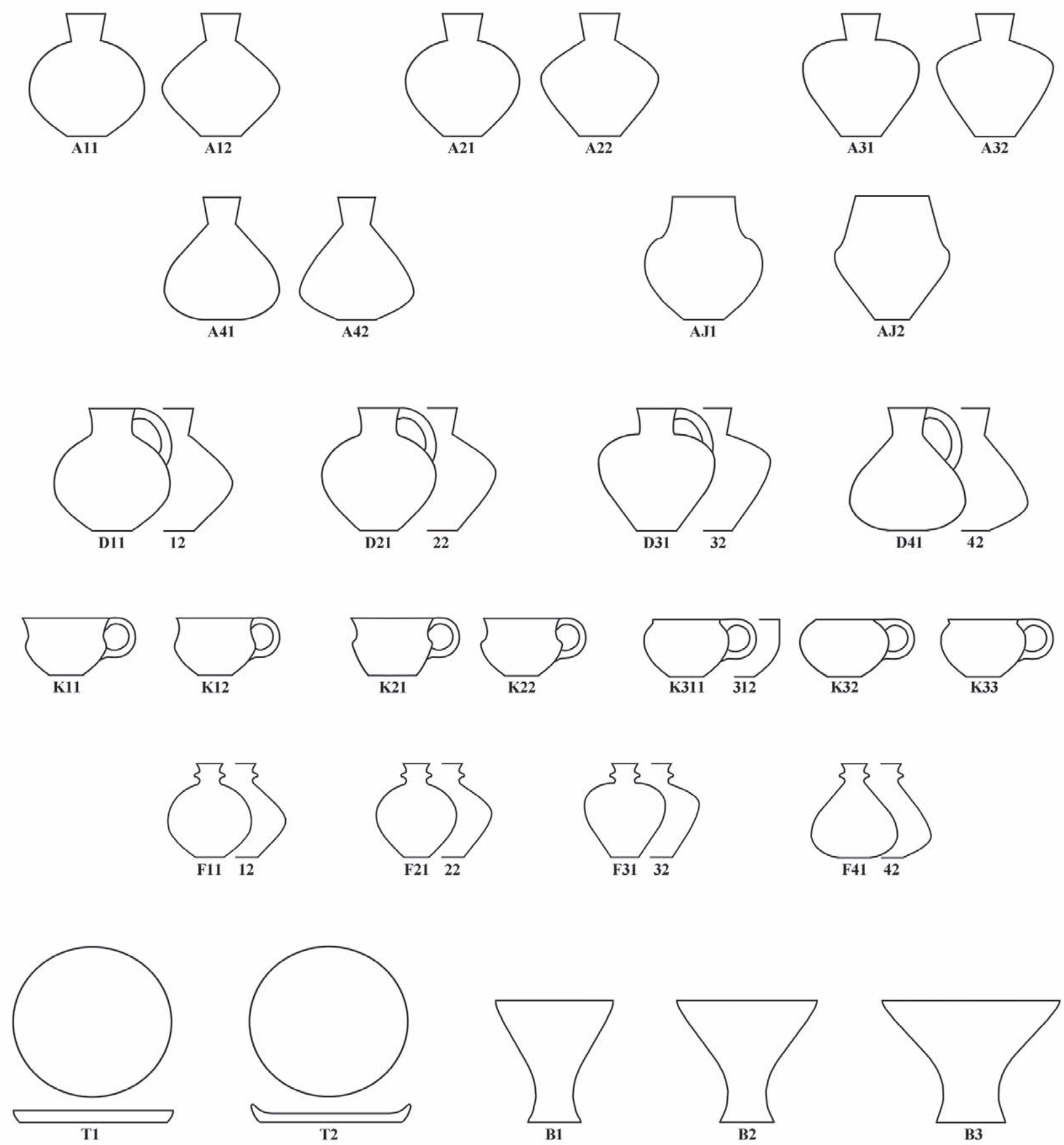

Ryc. 7. Typologia amfor, dzbanów, kubków, flasz z kryzą, talerzy oraz bębnów kultury pucharów lejkowatych. Rys. E. Dreczko

Fig. 7. Typology of amphorae, jugs, mugs, collared flasks, plates and drums of the Funnel Beaker culture. Drawn by E. Dreczko 

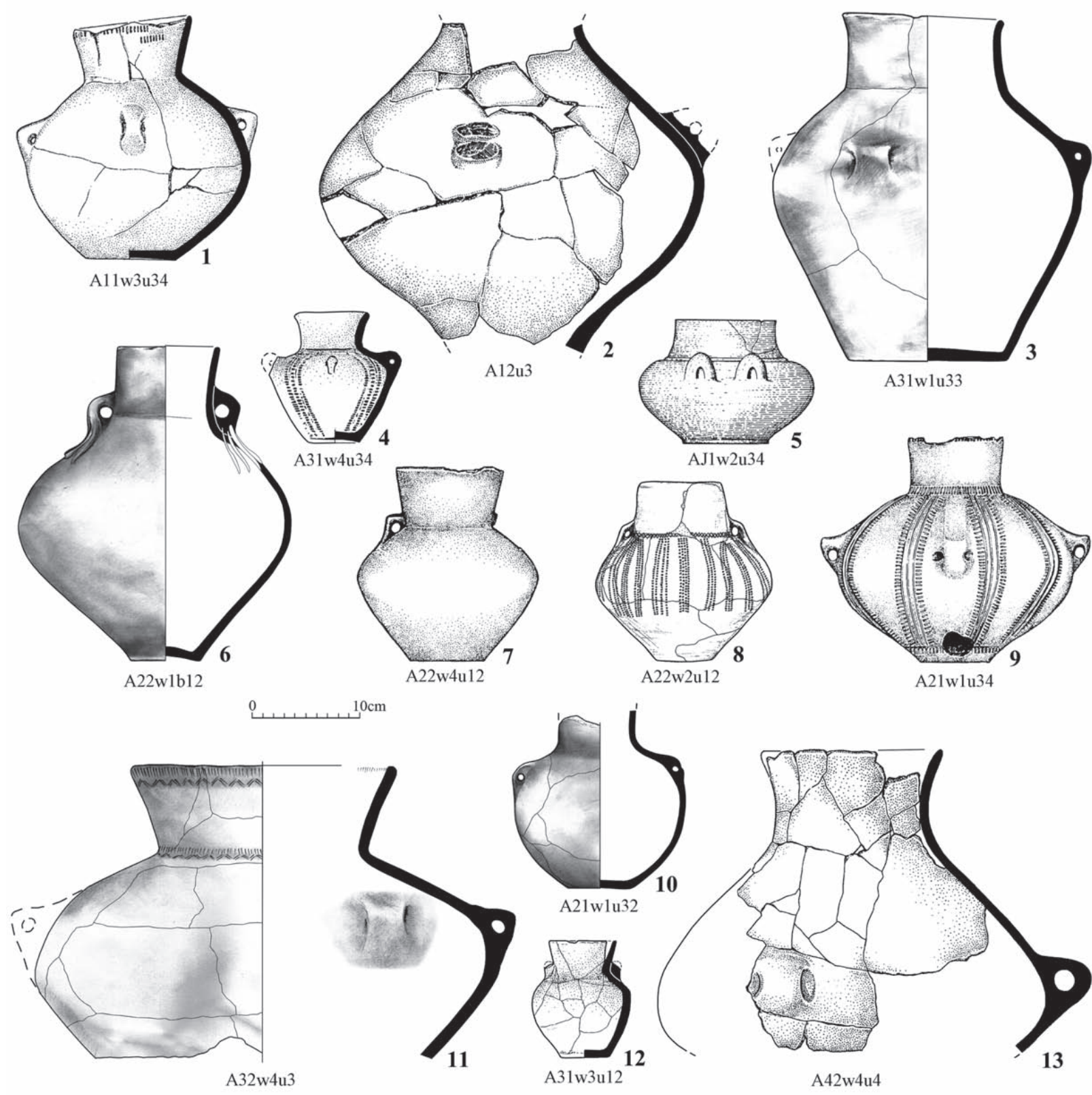

Ryc. 8. Amfory z dolnośląskich stanowisk kultury pucharów lejkowatych.

1, 13 - Strachów stan. 2, gm. Kondratowice; 2 - Polwica stan. 4, 5 i Skrzypnik stan. 8, gm. Domaniów; 3 - Gniechowice stan. 8, gm. Katy Wrocławskie; 4 - Sulimów stan. 1, gm. Święta Katarzyna; 5 - Janówek stan. 1, gm. Jordanów Śląski; 6 - Mikołajowice stan. 14, gm. Legnickie Pole; 7, 9 - Gajków, gm. Czernica; 8 - Krzeptów

stan. 6, gm. Kąty Wrocławskie; 10 - Wrocław-Pracze stan. 4; 11 - Gądów stan. 1, gm. Katy Wrocławskie;

12 - Radłowice stan. 1, gm. Domaniów. Rys. N. Lenkow: 1, 13 - wg A. Kulczycka-Leciejewiczowa 1997, ryc. 79:12, 13; 2 - wg A. Kulczycka-Leciejewiczowa, E. Noworyta 2009, ryc. 19:5; 4 - T. Wiślański 1979, ryc. 96:7;

5 -wg W. Wojciechowski 1973, ryc. 22e; 7, 9 - wg W. Wojciechowski 1996, ryc. 3a, b; 8 - wg M. Konczewska,

P. Konczewski 2007, ryc. 4a; 12 - wg S. Pazda 1993, ryc. 5c

Fig. 8. Amphorae from Lower Silesian sites of the Funnel Beaker culture.

1, 13 - Strachów site 2, Kondratowice district; 2 - Polwica sites 4, 5 and Skrzypnik site 8, Domaniów district;

3 - Gniechowice site 8, Kąty Wrocławskie district; 4 - Sulimów site 1, Święta Katarzyna district; 5 - Janówek site 1, Jordanów Śląski district; 6 - Mikołajowice site 14 Legnickie Pole district; 7, 9 - Gajków, Czernica district;

8 - Krzeptów site 6, Kąty Wrocławskie district; 10 - Wrocław-Pracze site 4; 11 - Gądów site 1, Kąty Wrocławskie district; 12 - Radłowice site 1, Domaniów district. Drawn by N. Lenkow: 1, 13 - after A. Kulczycka-

Leciejewiczowa 1997, fig. 79:12, 13; 2 - after A. Kulczycka-Leciejewiczowa, E. Noworyta 2009, fig. 19:5;

4 - after T. Wiślański 1979, fig. 96:7; 5 - after W. Wojciechowski 1973, fig. 22e;7, 9 - after W. Wojciechowski 1996, fig. 3a, b; 8 - after M. Konczewska, P. Konczewski 2007, fig. 4a; 12 - after S. Pazda 1993, fig. 5c 

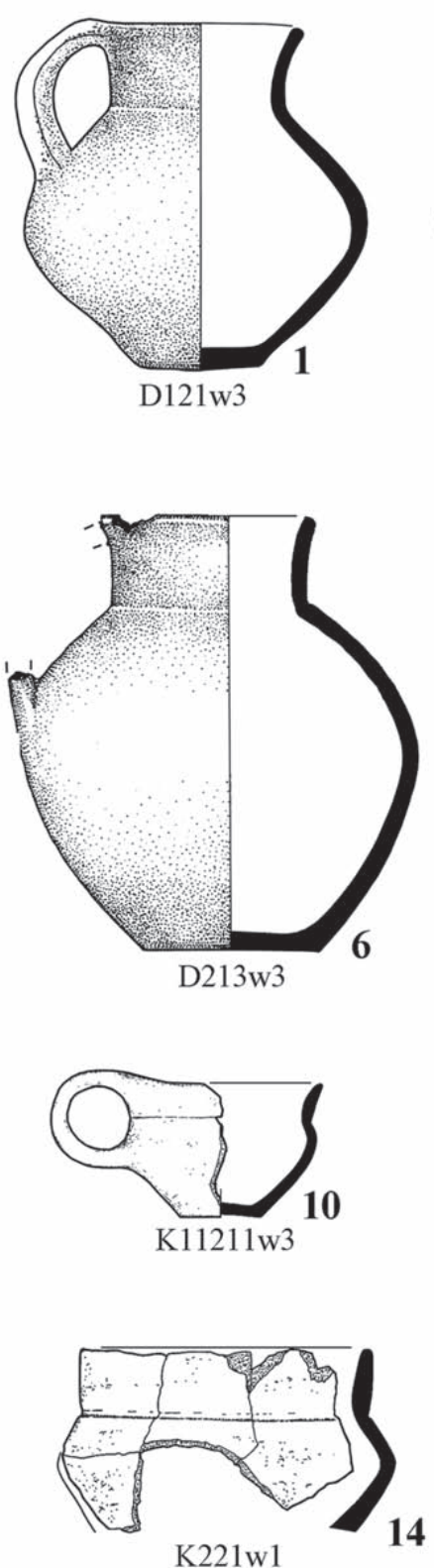
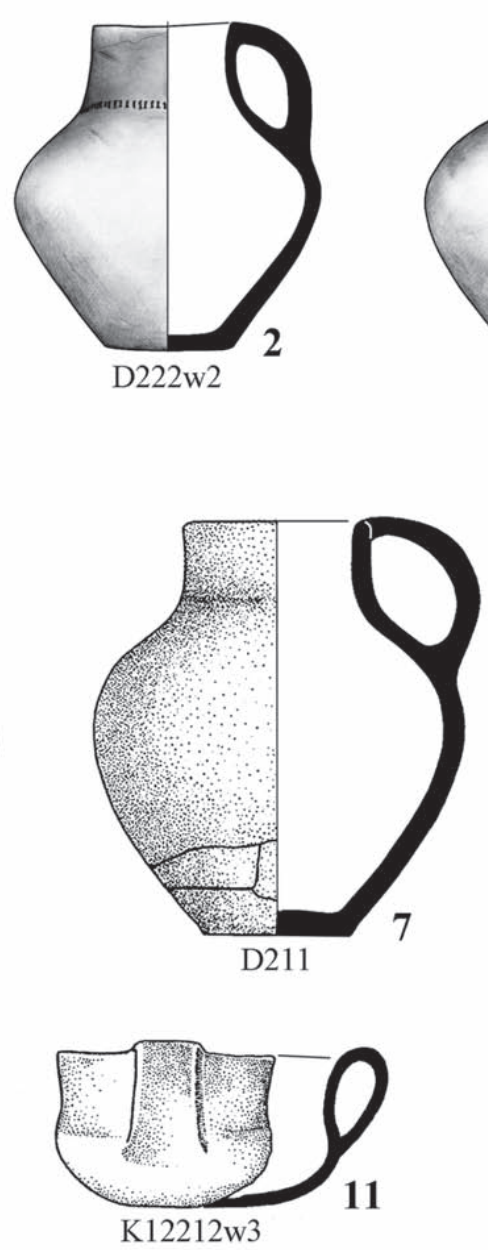
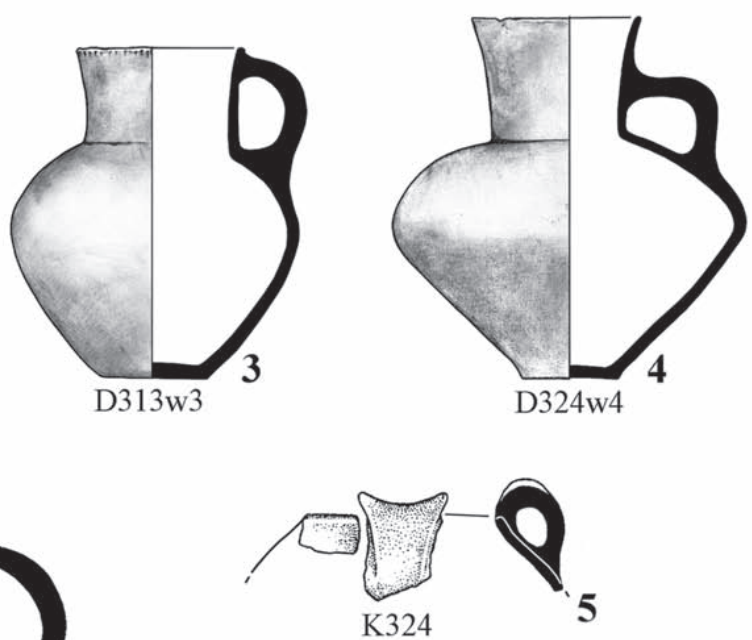

0
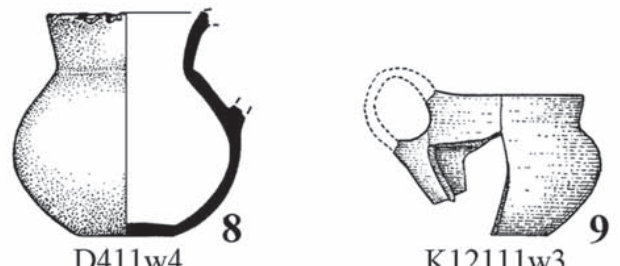

K12111w3

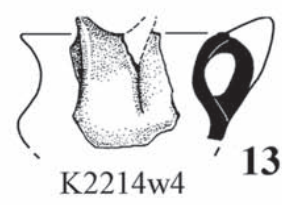

K12142w3
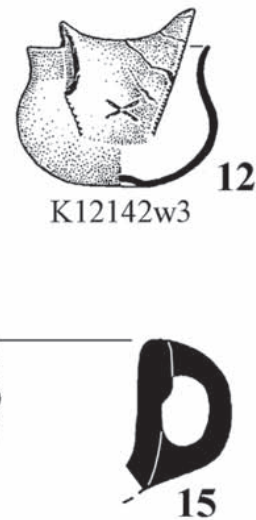

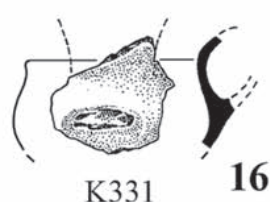

16

Ryc. 9. Dzbany (1-4, 6-8) oraz kubki $(5,9-16)$ z dolnośląskich stanowisk kultury pucharów lejkowatych. 1 - Stanowice, gm. Oława; 2 - Wrocław-Osobowice stan. 5; 3 - Źórawina stan. 2; 4 - Gniechowice stan. 8, gm. Kąty Wrocławskie; 5, 11, 12, 15, 16 - Strachów stan. 2, gm. Kondratowice; 6, 8, 13 - Polwica stan. 4, 5

i Skrzypnik stan. 8, gm. Domaniów; 7 - Krzeptów stan. 6, gm. Kąty Wrocławskie; 9 - Janówek stan. 1, gm. Jordanów Śląski; 10, 14 - Nowa Wieś Wrocławska stan. 4, gm. Katy Wrocławskie. Rys. N. Lenkow:

1 - wg T. Wiślański 1979, ryc. 96:5; 5, 11, 12, 15, 16 - wg A. Kulczycka-Leciejewiczowa 1997,

82:7, 38, 84:1; 96:2, 9; 6, 8, 13 - wg A. Kulczycka-Leciejewiczowa, E. Noworyta 2009, ryc. 7:1; 49:3; 69:4;

7 - wg M. Konczewska, P. Konczewski 2007a, ryc. 14d; 9 -wg W. Wojciechowski 1973, ryc. 35h;

10,14 - wg Dreczko w druku

Fig 9. Jugs (1-4, 6-8) and mugs (5, 9-16) from Lower Silesian sites of the Funnel Beaker culture.

1 - Stanowice, Oława district; 2 - Wrocław-Osobowice site 5; 3 - Źórawina site 2; 4 - Gniechowice site 8, gm.

Kąty Wrocławskie; 5, 11, 12, 15, 16 - Strachów site 2, Kondratowice district; 6, 8, 13 - Polwica sites 4, 5 and Skrzypnik site 8, Domaniów district; 7 - Krzeptów site 6, Kąty Wrocławskie district; 9 - Janówek site 1, Jordanów Śląski district; 10, 14 - Nowa Wieś Wrocławska site 4, Kąty Wrocławskie district.

Drawn by N. Lenkow: 1 - after T. Wiślański 1979, fig. 96:5; 5, 11, 12, 15, 16 - after A. Kulczycka-Leciejewiczowa 1997, fig. 82:7, 38, 84:1; 96:2, 9; 6, 8, 13 - after A. Kulczycka-Leciejewiczowa, E. Noworyta 2009, fig. 7:1; 49:3; 69:4; 7 - after M. Konczewska, P. Konczewski 2007a, fig. 14d; 9 - after W. Wojciechowski 1973, fig. 35h; 10, 14 - after Dreczko (in press) 
$\mathrm{K}-$ Kubek = naczynie jedno- lub dwuczłonowe o asymetrii poziomej, jedno lub wielouszne, spełniające warunki: R3>R1 i R1:H1 $\geq 1$ (ryc. 7);

$\mathrm{K} 1$ = jw., o esowatym profilu;

$\mathrm{K} 11=$ jw., gdy R1>R3;

$\mathrm{K} 111$ = jw., z wyraźnie zaznaczoną profilacją $\mathrm{R} 3: \mathrm{R} 2 \geq 1,1$;

$\mathrm{K} 112$ = jw., z nieznacznie zaznaczoną profilacją R3:R2<1,1 (ryc. 9:10);

$\mathrm{K} 12=$ jw., gdy $\mathrm{R} 1 \leq \mathrm{R} 3$;

K121 = jw., z wyraźnie zaznaczoną profilacją R3:R2 $\geq 1,1$ (ryc. 9:9, 12);

$\mathrm{K} 122$ = jw., z nieznacznie zaznaczoną profilacją R3:R2<1,1 (ryc. 9:11);

$\mathrm{K} 2$ = jw., o łamanym profilu (ostrozałomowe);

$\mathrm{K} 21$ = jw., gdy R1>R3;

$\mathrm{K} 211$ = jw., z wyraźnie zaznaczoną profilacją $\mathrm{R} 3: \mathrm{R} 2 \geq 1,1$;

$\mathrm{K} 212=\mathrm{jw}$, z nieznacznie zaznaczoną profilacją $\mathrm{R} 3: \mathrm{R} 2<1,1$;

$\mathrm{K} 22$ = jw., gdy $\mathrm{R} 1 \leq \mathrm{R} 3$;

K221 = jw., z wyraźnie zaznaczoną profilacją R3:R2 $\geq 1,1$ (ryc. 9:13, 14);

$\mathrm{K} 222$ = jw., z nieznacznie zaznaczoną profilacją $\mathrm{R} 3: \mathrm{R} 2<1$;

$\mathrm{K} 3=$ jw., o łukowatym profilu;

$\mathrm{K} 31=\mathrm{jw}$., z cylindrycznym wylewem R1=R2;

$\mathrm{K} 311$ = jw., $\mathrm{z}$ wyodrębnionym wylewem;

$\mathrm{K} 312$ = jw., z niewyodrębnionym wylewem (jednoczłonowy) (ryc. 9:15);

$\mathrm{K} 32$ = jw., z wylewem zagiętym do środka (jednoczłonowy) (ryc. 9:5);

$\mathrm{K} 33$ = jw., $\mathrm{z}$ wylewem lejowatym $\mathrm{H} 2: \mathrm{H} 4<0,2$ (ryc. 9:16);

$\mathrm{K} 1 \ldots . .1=$ jw., $\mathrm{z}$ uchem powyżej krawędzi wylewu;

$\mathrm{K} 1 \ldots . .2$ = jw., z uchem na wysokości krawędzi wylewu;

$\mathrm{K} 1 \ldots . .3$ = jw., z uchem poniżej krawędzi wylewu;

K1.....4 - jw., z uchem ansa lunata;

$\mathrm{K} 1 \ldots . .1-41$ = jw., $\mathrm{z}$ wyodrębnionym dnem;

$\mathrm{K} 1 \ldots . . .1-42$ = jw., z niewyodrębnionym dnem „kulistodenne”;

$\mathrm{F}-$ Flasza $\mathrm{z}$ kryzą = naczynie dwuczłonowe zaopatrzone $\mathrm{w}$ kryzę spełniające warunki: $\mathrm{R} 1 \geq \mathrm{R} 2$ oraz $\mathrm{R} 3>\mathrm{R} 1$ i oraz R3 $>$ R2 (ryc. 7);

$\mathrm{F} 1=$ jw., o symetrycznym brzuścu: $0,90 \leq \mathrm{H} 3: \mathrm{H} 5<1,00$;

F11 = jw., o łukowato wygiętym brzuścu (ryc. 10:1);

F12 = jw., o łamanym brzuścu (ostrozałomowe) (ryc. 10:2);

$\mathrm{F} 2$ = jw., o lekko podkreślonej mikromorfologicznie asymetrii brzuśca: $0,60 \leq \mathrm{H} 3: \mathrm{H} 5<0,9$;

$\mathrm{F} 21=$ jw., o łukowato wygiętym brzuścu (ryc. 10:3);

F22 = jw., jw. o łamanym brzuścu (ostrozałomowe) (ryc. 10:5, 11);

F3 = jw., o wyraziście podkreślonej mikromorfologicznie asymetrii brzuśca: H3:H5<0,60;

F31 = jw., o łukowato wygiętym brzuścu (ryc. 10:10);

$\mathrm{F} 32=\mathrm{jw}$. , jw. o łamanym brzuścu (ostrozałomowe);

F4 = jw., o wyraziście podkreślonej mikromorfologicznie asymetrii brzuśca, gdy H3>H5;

$\mathrm{F} 41$ = jw., o łukowato wygiętym brzuścu (ryc. 10:12);

$\mathrm{F} 42$ = jw., jw. o łamanym brzuścu (ostrozałomowe) (ryc. 10:4);

$\mathrm{T}-$ talerz $=$ naczynie jednoczłonowe, spełniające warunki: $2 \mathrm{xH} 6 \leq \mathrm{H} 1$ (ryc. 7);

$\mathrm{T} 1=$ jw., płaski: $\mathrm{H} 1=\mathrm{H} 6$ (ryc. 10:8);

$\mathrm{T} 2$ = jw., głęboki H1>H6;

T21 = jw., o łagodnym spojeniu ścianki bocznej z dnem (ryc. 10:7, 9);

T22 = jw., o podkreślonej odrębności morfologicznej ścianki bocznej i dna (ryc. 10:6); 


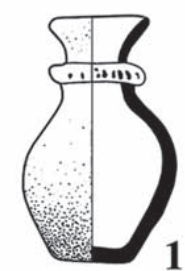

F11w5

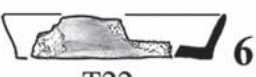

T22

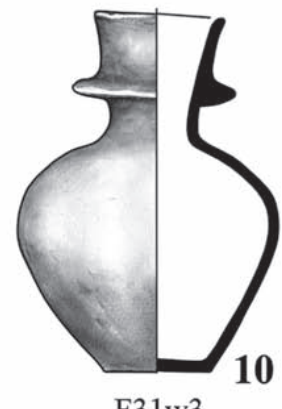

F31w3

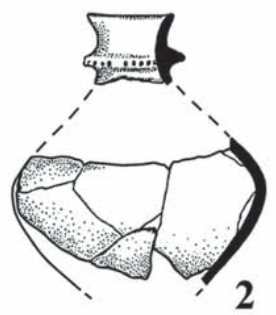

F12w4

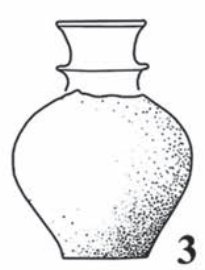

F21

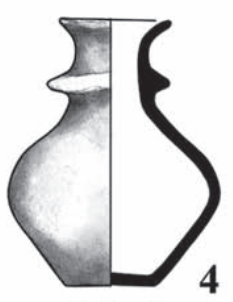

F42w5

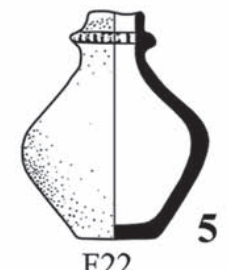

F22

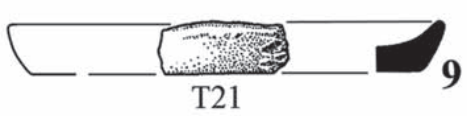

$\mathrm{T} 1$

8
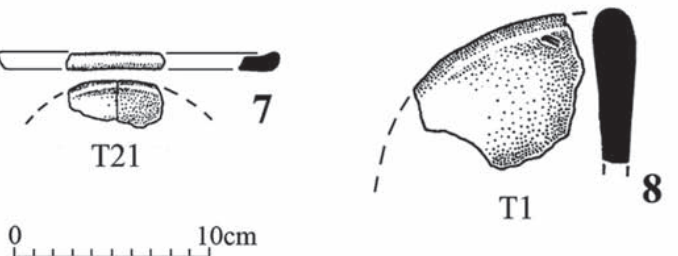

T21

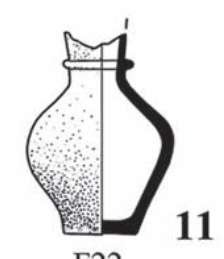

F22
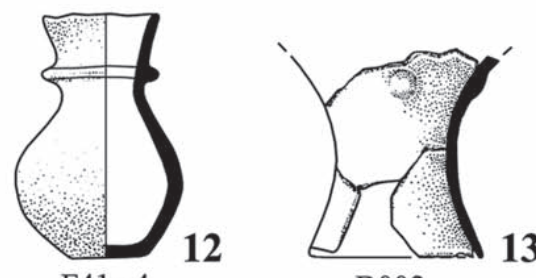

B002

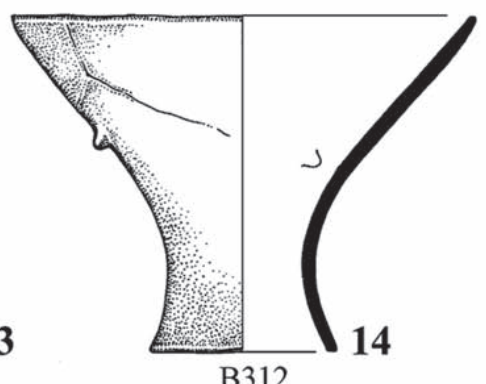

Ryc. 10. Flasze z kryzą (1-5, 10-12), talerze (6-9) i bębny (13-14) z dolnośląskich stanowisk kultury pucharów lejkowatych.

1 - Stanowice, gm. Oława; 2, 7-9, 13 - Strachów stan. 2, gm. Kondratowice; 3 - Strzelin stan. 11; 4 - Kuchary, gm. Domaniów; 5, 11 - Jordanów Śląski stan. 5; 6 - Stary Zamek stan. 7, gm. Sobótka; 10 - Rolantowice stan. 2, gm. Kobierzyce; 12 - Wrocław-Osobowice stan. 5; 14 - Polwica stan. 4, 5 i Skrzypnik stan. 8, gm. Domaniów. Rys. N. Lenkow: 1, 5, 11, 12- T. Wislański 1979, ryc. 96:11, 13; 97:3, 10; 2, 7-9, 13 - wg A. Kulczycka-Leciejewiczowa 1997, ryc. 82:26, 34; 96:34, 35, 37; 3 - wg M. Rabshl 1944, ryc. 8.1; 10 - wg H. Seger 1926, tabl. XXX:1; 14 - wg A. Kulczycka-Leciejewiczowa, E. Noworyta 2009, ryc. 49:4

Fig. 10. Collared flasks (1-5, 10-12), plates (6-9) and drums (13-14) from Lower Silesian sites of the Funnel Beaker culture.

1 - Stanowice, Oława district; 2, 7-9, 13 - Strachów site 2, Kondratowice district; 3 - Strzelin site 11; 4 - Kuchary, Domaniów district; 5, 11 - Jordanów Śląski site 5; 6 - Stary Zamek site 7, Sobótka district; 10 - Rolantowice site 2, Kobierzyce district; 12 - Wrocław-Osobowice site 5; 14 - Polwica sites 4, 5 and Skrzypnik site 8, Domaniów district. Drawn by N. Lenkow: 1, 5, 11, 12- after T. Wislański 1979, fig. 96:11, 13; 97:3, 10; 2, 7-9, 13 - after A. Kulczycka-

Leciejewiczowa 1997, fig. 82:26, 34; 96:34, 35, 37; 3 - after M. Rabshl 1944, fig. 8.1; 10 - after H. Seger 1926, table XXX:1; 14 - after A. Kulczycka-Leciejewiczowa, E. Noworyta 2009, fig. 49:4

$\mathrm{B}-$ bęben = naczynie dwuczłonowe pozbawione dna, spełniające warunki którejkolwiek z innych grup typologicznych (ryc. 7);

$\mathrm{B} 1=$ jw., gdy $\mathrm{R} 1: \mathrm{H} 1<1,0$;

$\mathrm{B} 2=$ jw., gdy $1,0 \leq \mathrm{R} 1: \mathrm{H} 1 \leq 1,2$;

$\mathrm{B} 3=$ jw., gdy R1:H1>1,2;

$\mathrm{B} 11 ; 21 ; 31=$ jw., gdy $\mathrm{H} 1: \mathrm{H} 2<1,5$;

B12; 22; $32=$ jw., gdy H1:H2>1,5;

B111; 121;211;221;311; $321=$ jw., z uchami;

B112; 122; 212; 222; 312; 322 = jw., z guzami (ryc. 10:13, 14); 
Główne typy, podtypy oraz warianty (z wyjątkiem bębnów i talerzy) można rozszerzyć o oznaczone małą literą alfabetu oraz cyfrą szczegółowe określenie ukształtowania wyodrębnionego wylewu (w), ilość, a także miejsce umieszczenia uch (u) oraz obecność nóżek (n) według następującego systemu (ryc. 11):

$\mathrm{w} 1=\mathrm{z}$ cylindrycznym wylewem $\mathrm{R} 1=\mathrm{R} 2$;

$\mathrm{w} 2=\mathrm{z}$ wylewem zwężającym się do środka $\mathrm{R} 2>\mathrm{R} 1$;

$\mathrm{w} 3=\mathrm{z}$ lejkowatym wylewem $\mathrm{R} 1 / \mathrm{R} 2<1,2$;

w4 $=$ ze średnio lejkowatym wylewem $1,2 \leq \mathrm{R} 1 /$ $\mathrm{R} 2<1,4$; $\mathrm{w} 5=\mathrm{z}$ silnie lejkowatym wylewem R1/R2>1,4;

$\mathrm{u} 1=\mathrm{z}$ uchami na załomie wylewu i brzuśca;

$\mathrm{u} 2=\mathrm{z}$ uchami $\mathrm{w}$ pozycji górnobarkowej;

$\mathrm{u} 3=\mathrm{z}$ uchami w pozycji dolnobarkowej;

$\mathrm{u} 4=\mathrm{z}$ uchami na największej wydętości brzuśca;

u1-42 = jw., dwuuszne;

u1-43 = jw., trójuszne;

u1-44 = jw., czterouszne;

$\mathrm{u} 1-4 \mathrm{n}=$ jw., z n liczbą uch;

$\mathrm{n} 1=$ na jednej nóżce;

n2 = na dwóch nóżkach;

n3 = na trzech nóżkach;

nn - na n liczbie nóżek;

Zastosowanie przedstawionej typologii, podobnie jak w przypadku analogicznych opracowań opartych na wskaźnikach metrycznych, do analiz silnie rozdrobnionych zespołów łączy się z utrud-
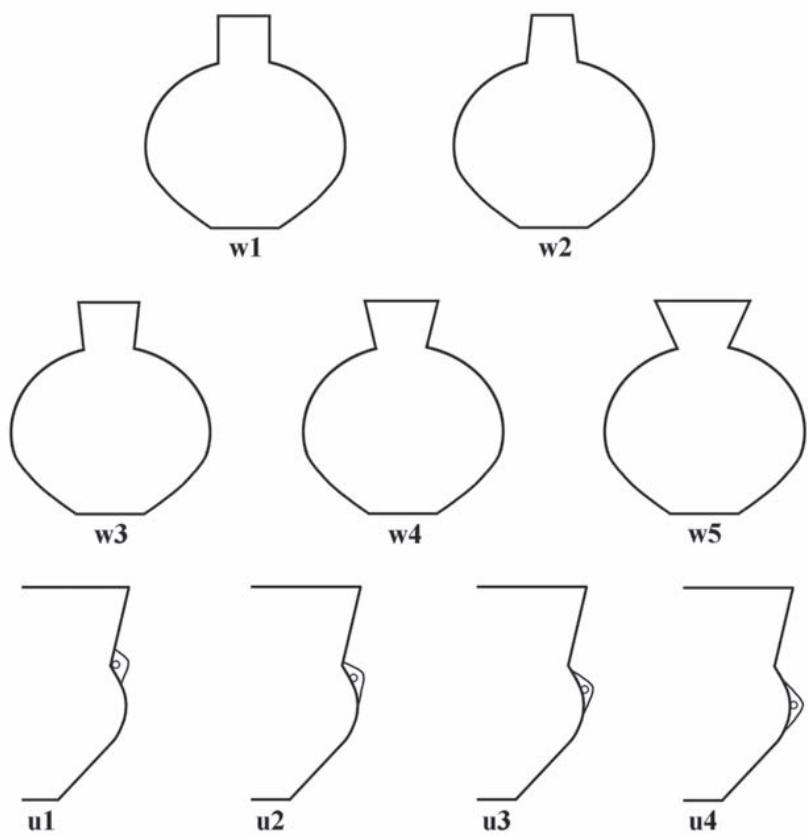

Ryc. 11. Schemat zapisu typów wylewów oraz lokalizacji umieszczenia i liczby uch na przykładzie pucharów lejkowatych i amfor. Rys. E. Dreczko

Fig. 11. Diagram of types of rims, points of attachment and number of ears on the example of funnel beakers and amphorae. Drawn by E. Dreczko

nieniami. W szczególności dotyczy to identyfikacji mis oraz waz, których fragmentaryczny stan zachowania umożliwia pełne odtworzenie kształtu profilu, lecz nie pozwala na określenie całkowitej wysokości naczynia. W takich wypadkach możliwe jest zastosowanie kategorii pośredniej W/M oraz uściślenie podtypu, odmiany czy wariantu, np. W/M11.

\section{ZAKOŃCZENIE}

Zaproponowana typologia naczyń KPL stworzona została na bazie znalezisk ceramicznych społeczności tej kultury z obszaru Dolnego Śląska. Jej otwarta struktura umożliwia rozbudowę istniejących typów oraz dołączanie nowych w przypadku odkrycia niemieszczących się w jej ramach naczyń. Daje to możliwość jej wykorzystania i dostosowa- nia do analiz ceramiki ,pucharowej” także z innych obszarów.

Zarysowana problematyka oraz przedstawiona propozycja typologii jest częścią powstającej monografii kultury pucharów lejkowatych na Dolnym Śląsku².

2 Ewa Dreczko, Społeczności kultury pucharów lejkowatych na Dolnym Ślasku, praca doktorska realizowana w Instytucie Archeologii Uniwersytetu Wrocławskiego. 
TYPOLOGIA FORM NACZYŃ KULTURY PUCHARÓW LEJKOWATYCH Z OBSZARU DOLNEGO ŚLĄSKA

Tabela 1. Zestawienie analizowanych naczyń z dolnośląskich stanowisk kultury pucharów lejkowatych

\begin{tabular}{|c|c|c|c|c|}
\hline Lp. & Stanowisko & G mina & $\begin{array}{l}\text { Liczba } \\
\text { naczyń }\end{array}$ & L iteratura \\
\hline 1 & Bielany Wrocławskie 11 & Kobierzyce & 1 & Seger 1916a, 46; ryc. 190 \\
\hline 2 & Bielany Wrocławskie 35 & Kobierzyce & 1 & Cholewa, Wojciechowski 2002, 193, ryc. 6b \\
\hline 3 & Biskupice Podgórne 1 & Kobierzyce & 2 & Kopeć-Żygadło, Żygadło 2006, ryc. 5:1, 4 \\
\hline 4 & Cesarzowice 2 & $\begin{array}{l}\text { Katy } \\
\text { Wrocławskie }\end{array}$ & 1 & Furmanek i inni 2012 , ryc. $12: 1$ \\
\hline 5 & Chociwel 1 & Strzelin & 5 & Cholewa 1998 \\
\hline 6 & Gądów 1 & \begin{tabular}{|l|} 
Katy \\
Wrocławskie
\end{tabular} & 1 & niepublikowane $^{1}$ \\
\hline 7 & Gajków b.n. & Czernica & 2 & Wojciechowski 1996 \\
\hline 8 & Gniechowice $8^{2}$ & $\begin{array}{l}\text { Katy } \\
\text { Wrocławskie }\end{array}$ & 8 & niepublikowane \\
\hline 11 & Groblice 1 & $\begin{array}{l}\text { Święta } \\
\text { Katarzyna }\end{array}$ & 1 & niepublikowane \\
\hline 12 & Jankowice 3 & Oława & 1 & niepublikowane \\
\hline 13 & Janówek 1 & Jordanów Śląski & 22 & Wojciechowski 1973 \\
\hline 14 & Jordanów Śląski 4 & Jordanów Śląski & 2 & $\begin{array}{l}\text { Seger 1926, 206-207, ryc. 9, tabl. XXVII, } \\
\text { XXVII }\end{array}$ \\
\hline 15 & Jordanów Śląski 5 & Jordanów Śląski & 6 & $\begin{array}{l}\text { Seger 1906, tabl. VIII: 1-3, 6, 10; 1916a, } 27 \\
\text { ryc. } 86 ; 47 \text { ryc. } 198\end{array}$ \\
\hline 16 & Kilianów b.n. & $\begin{array}{l}\text { Katy } \\
\text { Wrocławskie }\end{array}$ & 4 & Richter 1907 \\
\hline 17 & Kojęcin-Jaksonów 1 & Borów & 1 & Umbreit 1937, 102; tab.44c \\
\hline 18 & Królikowice 3 & Kobierzyce & 1 & Butent 1989,35 ; ryc. 5 c \\
\hline 19 & Krzeptów 6 & \begin{tabular}{|l|} 
Katy \\
Wrocławskie
\end{tabular} & 3 & Konczewska, P. Konczewski 2007a, 2007b \\
\hline 20 & Kuchary b.n. & Domaniów & 1 & niepublikowane \\
\hline 21 & Małuszów 10 & Kobierzyce & 3 & Dreczko, Mozgała 2010 \\
\hline 24 & Mikołajowice 14 & Legnickie Pole & 1 & Umbreit 1937, 114; tabl. 45d \\
\hline 25 & Muszkowice 18 & Ciepłowody & 3 & $\begin{array}{l}\text { Wojciechowski, Cholewa 2011, } 100 \text { ryc. } 8 \text {; } \\
102 \text { ryc. } 11\end{array}$ \\
\hline 26 & Nowa Wieś Wrocławska 4 & $\begin{array}{l}\text { Kąty } \\
\text { Wrocławskie }\end{array}$ & 30 & Dreczko w druku \\
\hline
\end{tabular}


EWA DRECZKO

\begin{tabular}{|c|c|c|c|c|}
\hline 27 & Piskorzówek 11 & Domaniów & 1 & Czarniak 2014, 162 ryc. 9a \\
\hline 28 & Polwica 4, 5 i Skrzypnik 8 & Domaniów & 42 & Kulczycka-Leciejewiczowa, Noworyta 2009 \\
\hline 29 & Radłowice 1 & Domaniów & 1 & Pazda 1993, 427 ryc. 5c; tabl. XXXI:2, 3 \\
\hline 30 & Radłowice 6 & Domaniów & 2 & Seger 1926, tabl. XXXI:1, 2 \\
\hline 31 & Rolantowice b.n. & Kobierzyce & 1 & Seger 1926, 210; tabl. XXX:1 \\
\hline 32 & Sienice 17 & Łagiewniki & 1 & niepublikowane \\
\hline 33 & Stanowice b.n. & Oława & 2 & Wiślański 1979, 182 ryc. $96: 5,13$ \\
\hline 34 & Stary Zamek $7^{3}$ & Sobótka & 7 & niepublikowane \\
\hline 35 & Strachów 2 & Kondratowice & 74 & $\begin{array}{l}\text { Umbreit 1937, 110; tabl. 42o; } \\
\text { Kulczycka-Leciejewiczowa } 1997\end{array}$ \\
\hline 39 & Strachów 6 & Kondratowice & 1 & Kulczycka-Leciejewiczowa 1997 \\
\hline 40 & Strzelin 11 & Strzelin & 2 & Rabshal 1944 \\
\hline 41 & Strzelin 19 & Strzelin & 1 & Wojciechowski, Cholewa 2000, tabl. XIe \\
\hline 42 & Sulimów 1 & \begin{tabular}{|l} 
Święta \\
Katarzyna
\end{tabular} & 2 & Umbreit 1937, 105, 109; tabl. 44g, h \\
\hline 43 & Tomice 1 & Jordanów Śląski & 4 & Romanow 1973 \\
\hline 44 & Trzebnik 10 & Łagiewniki & 3 & Seger 1916a, 48; 47 ryc. 191-193 \\
\hline 45 & Trzebnik 11 & Łagiewniki & 1 & Seger 1916a, 48; 43 ryc. 184 \\
\hline 46 & Wilczków 2 & Żórawina & 1 & niepublikowane \\
\hline 47 & Wilczków 3 & Żórawina & 1 & Umbreit 1937, 100; tabl. 42a \\
\hline 48 & Wilczkowice 8 & Jordanów Śląski & 1 & Umbreit 1937,$110 ;$ tabl. $45 b$ \\
\hline 49 & Wilkowice 8 & Żórawina & 1 & Kopeć i inni 2001, 222 ryc. 5:6 \\
\hline 50 & Wojkowice 15 & Żórawina & 5 & Stanisławski, Wojnicka 2014 \\
\hline 51 & $\begin{array}{l}\text { Wrocław-Grabiszyn } \\
\text { (cmentarz) }\end{array}$ & Wrocław & 1 & Seger 1924, 74, 75; tabl. VII:8 \\
\hline 52 & Wrocław-Kuźniki 1/2 & Wrocław & 1 & Umbreit 1937, 105; tabl. 44d \\
\hline 53 & Wrocław-Muchobór Mały & Wrocław & 1 & Prus 1977,153 ryc. $2 c$ \\
\hline
\end{tabular}


TYPOLOGIA FORM NACZYŃ KULTURY PUCHARÓW LEJKOWATYCH Z OBSZARU DOLNEGO ŚLĄSKA

\begin{tabular}{|l|l|l|r|l|}
\hline 54 & Wrocław-Osobowice 5 & Wrocław & 3 & Hoffman 1941, tabl. 1: 6, Rabshal 1944 \\
\hline 55 & Wrocław-Partynice 1 & Wrocław & 2 & Seger 1916a: 45, ryc. 185, 186 \\
\hline 56 & Wrocław-Partynice 6 & Wrocław & 9 & Kulczycka-Leciejewiczowa 2001 \\
\hline 57 & $\begin{array}{l}\text { Wrocław-Pracze } \\
\text { Odrzańskie 4 }\end{array}$ & Wrocław & 3 & Seger 1916b \\
\hline 58 & Wrocław-Rędzin 5 & Wrocław & 1 & Geschwendt 1935, 117 ryc. 11 \\
\hline 59 & Wrocław-ul. Sztabowa & Wrocław & 1 & niepublikowane \\
\hline 60 & Zarzyca 2 & Kondratowice & 2 & Prus 1977 \\
\hline 61 & Zarzyca 6 & Kondratowice & 5 & Czerniak 2008 \\
\hline 62 & Żerniki Wielkie 4 & Źórawina & 1 & Prus 1975, 54 ryc. 14k \\
\hline 63 & Żórawina 2 & Żórawina & 1 & niepublikowane \\
\hline
\end{tabular}

1 Fragment wylewu badanego naczynia (ryc. 9:10) został opublikowany przez W. Wojciechowskiego jako pochodzący ze stanowiska nr 1 w Tyńcu nad Ślęzą (1968: 131 tabl. I:9)

2 Stanowisko znane w literaturze jako Gniechowice, stan. 2 (por. Kulczycka-Leciejewiczowa, Romanow 1985). Nowy numer nadany został w wyniku inwentaryzacji w ramach AZP.

3 Stanowisko znane w literaturze jako Stary Zamek, stan. 2a (por. Kulczycka-Leciejewiczowa, Romanow 1985). Nowy numer nadany został w wyniku inwentaryzacji w ramach AZP.

\section{BIBLIOGRAFIA}

Bukowska-Gedigowa J. 1975. Kultura pucharów lejkowatych w dorzeczu górnej Odry. Przeglad Archeologiczny 23, 83-186.

Butent B. 1989. Cmentarzysko szkieletowe z neolitu i wczesnej epoki brązu w Królikowicach, woj. Wrocław, stanowisko 3. Silesia Antiqua 31, 33-45.

Cholewa P. 1998. Osady neolityczne na stanowisku nr 1 w Chociwelu, gm. Strzelin. Studia Archeologiczne 30, 81-168.

Cholewa P., Wojciechowski W. 2002. Wyniki badań na osadzie kultury pucharów lejkowatych przy ul. Czekoladowej we Wrocławiu. Ślaskie Sprawozdania Archeologiczne 44, 187-195.

Czarniak K. 2008. Osada kultury pucharów lejkowatych na stan. 6 w Zarzycy, pow. Strzelin. Ślaskie Sprawozdania Archeologiczne 50, 107-122.

Czarniak K. 2014. Osadnictwo neolityczne oraz z przełomu neolitu i wczesnego okresu epoki brązu na stanowisku 11 w Piskorzówku, gm. Domaniów. (W:) B. Gediga (red.), Archeologiczne Zeszyty Autostradowe, z. 15. Badania na autostradzie A-4, cz. XII. Wrocław, 153-241.

Dreczko E. w druku. Osada społeczności kultury pucharów lejkowatych. (W:) B. Gediga (red.), Osadnictwo neolityczne na stanowisku 4 w Nowej Wsi Wrocławskiej, gm. Katy Wrocławskie. Archeologiczne Zeszyty Autostradowe, z. 20.

Dreczko E., Mozgała M. 2010. Małuszów stan. 10, gm. Katy Wrocławskie. Opracowanie wyników ratowniczych badań wykopaliskowych zwiazanych z budowa obwodnicy Tyńca Małego i Małuszowa. Maszynopis w Archiwum Instytutu Archeologii Uniwersytetu Wrocławskiego.

Dreczko E., Mozgała M. 2014. Ślady aktywności grup ludzkich młodszej epoki kamienia. (W:) M. Masojć (red.), Obozowiska, osady, wsie. Wrocław-Widawa 17. Wrocław, 79-87.

Furmanek M., Masojć M., Piekalski J. 2012. Wyniki badań ratowniczych prowadzonych przez Instytut Archeolo- 
gii Uniwersytetu Wrocławskiego w związku z budową Autostradowej Obwodnicy Wrocławia. (W:) S. Kadrow (red.), Raport 2007-2008. Warszawa, 370-376.

Geschwendt F. 1935. Der Bagger als Altertumsforscher. Altschlesische Blätter 10, z. 5, 116-119, Abb. 11.

Gumiński W. 1989. Gródek Nadbużny. Osada kultury pucharów lejkowatych. Wrocław-Warszawa-KrakówGdańsk-Łódź.

Hoffman W. 1941. Die vorgeschichtliche Funde von Breslau-Oswitz und Ransern, Kr. Breslau. Altschlesien 10, 7-10.

Jankowska D. 1980. Kultura pucharów lejkowatych na Pomorzu Środkowym. Grupa Łupawska. Poznań.

Konczewska M., Konczewski P. 2006. Nowoodkryte stanowisko wielokulturowe w Krzeptowie, gm. Kąty Wrocławskie. Ślaskie Sprawozdania Archeologiczne 48, 135-153.

Konczewska M., Konczewski P. 2007a. Nowoodkryte stanowisko wielokulturowe w Krzeptowie, gm. Katty Wrocławskie. Ślaskie Sprawozdania Archeologiczne 48, 135-153.

Konczewska M., Konczewski P. 2007b. Osada neolityczna w Krzeptowie, gm. Kąty Wrocławskie w świetle badań archeologicznych w latach 2005-2006. Ślaskie Sprawozdania Archeologiczne 49, 53-60.

Kopeć K., Nowaczyk K., Nowaczyk L., Wodejko E. 2001. Wstępne wyniki badań wykopaliskowych prowadzonych na wielokulturowym stanowisku Wilkowie 8, gm. Żórawina, woj. dolnośląskie. (W:) Z. Bukowski (red.), Raport 96-99. Warszawa, 215-238.

Kopeć-Żygadło K., Żygadło L. 2006. Sprawozdanie z badań wykopaliskowych przeprowadzonych na stanowisku 1 w Biskupicach Podgórnych, gm. Katy Wrocławskie, woj. dolnośląskie w roku 2003. (W:) Z. Bukowski, M. Gerlach (red.), Raport 2003-2004. Warszawa, 199-218.

Kośko A. 1981. Udziat południowo-wschodnioeuropejskich wzorców kulturowych $w$ rozwoju niżowych społeczeństw kultury pucharów lejkowatych. Grupa matewska. Poznań.

Kulczycka-Leciejewiczowa A. 1997. Strachów. Osiedla neolitycznych rolników na Ślasku. Wrocław.

Kulczycka-Leciejewiczowa A. 2001. Neolityczni użytkownicy stanowiska. (W:) L. Leciejewicz (red.), Od neolitycznego obozowiska do średniowiecznej wsi. Badania archeologiczne we Wrocławiu-Partynicach. Wrocław, 17-34.

Kulczycka-Leciejewiczowa A., Noworyta E. 2009. Osadnictwo neolityczne w Polwicy i Skrzypniku, powiat Oława. (W:) B. Gediga (red.), Archeologiczne Zeszyty
Autostradowe, zeszyt 8. Badania na autostradzie A4, część VI. Wrocław, 7-114.

Kulczycka-Leciejewiczowa A., Romanow J. 1985. Wczesnoneolityczne osiedla w Gniechowicach i Starym Zamku. Silesia Antiqua 27, 9-81.

Pazda S. 1993. Groby neolityczne na stanowisku nr 1 w Radłowicach, gm. Domaniów, woj. Wrocławskie. Ślaskie Sprawozdania Archeologiczne 34, 421-433.

Procházková P., Šmíd M. 1999. Navrh typologie keramiky kultury lidu s nálevkovitými poháry na Moravě. Pravěk 9, 159-179.

Prus O. 1975. Wielokulturowa osada we Wrocławiu-Muchoborze Małym. Silesia Antiqua 17, 149-167.

Prus O. 1977. Zarzyca, gmina Kondratowice, woj., Wrocław. Silesia Antiqua 19, 343, 348-349.

Rabshal M. 1944. Trichterbecher und Kragenflaschen. Altschlesische Blätter 1944, z. 2, 18-19.

Richter J. 1907. Der fund von Landau, kreis Neumarkt. Schlesiens Vorzeit in Bild und Schrift, N. F. 4, 44-45.

Romanow J. 1973. Osada kultury pucharów lejkowatych. (W:) J. Romanow, K. Wachowski, Miszkiewicz (red.), Tomice, pow. Dzierżoniów. Wielokulturowe stanowisko archeologiczne. Wrocław, 23-100.

Rzepecki S. 2004. Społeczności środkowoneolitycznej kultury pucharów lejkowatych na Kujawach. Poznań.

Seger H. 1906. Die Steinzeit in Schlesien. Archiv für Antropologie 5, 116-141.

Seger H. 1916a. Die keramischen Stilarten der jüngeren Steinzeit Schlesiens. Schlesiens Vorzeit in Bild und Schrift, NF 7, 1-89.

Seger H. 1916b. Ein Brunnenfund aus der Steinzeit. Schlesiens Vorzeit in Bild und Schrift, NF 7, 90-92.

Seger H. 1924. Auf den Spuren alter Sieldungen. 4. Breslau, Gräbschener Friedhof. Altschlesien 1, z. 2, 74-75.

Seger H. 1926. Aus der Steinzeit. Altschlesien 1, 199-217.

Stanisławski A., Wojnicka D. 2012. Osadnictwo neolityczne na stanowisku Wojkowice 15, gmina Żórawina. (W:) B. Gediga (red.), Archeologiczne Zeszyty Autostradowe 12, Badania na autostradzie A4, część VI. Wrocław, 7-179.

Szmyt M. 1996. Społeczności kultury amfor kulistych na Kujawach. Poznań.

Umbreit C. 1937. Neue Forschungen zur ostdeutschen Steinzeit und frühen Bronzezeit. Die Ausgrabung des steinzeitlichen Dorfes zu Berlin-Britz. Leipzig.

Wiślański T. 1979. Kształtowanie się miejscowych kultur rolniczo-hodowlanych. Plemiona kultury pucharów lejkowatych. (W:) W. Hensel, T. Wiślański (red.), Prahistoria ziem polskich, t. II. Neolit. Wrocław-Warszawa-Kraków-Gdańsk, 165-260. 
Wojciechowski W. 1968. Ze studiów nad kulturą pucharów lejowatych na Dolnym Śląsku. Zagadnienie periodyzacji. Archeologia Polski 13, z. 1, 125-150.

Wojciechowski W. 1973. Osada ludności kultury pucharów lejkowatych w Janówku pow. Dzierżoniów. Studia Archeologiczne 6.

Wojciechowski W. 1996. Neolityczny depozyt wotywny z Gajkowa, woj. Wrocław. Silesia Antiqua 38, 9-19.
Wojciechowski W., Cholewa P. 2000. Osady neolityczne na stanowisku 19 w Strzelinie, Studia Archeologiczne 32, 126.

Wojciechowski W., Cholewa P. 2011. Grobowce megalityczne u podnóża Sudetów. (W:) H. Kowalewska-Marszałek, P. Włodarczak (red.), Kurhany i obrzadek pogrzebowy w IV-II tysiacleciu p.n.e. Kraków, 91-107.

\section{TYPOLOGY OF VESSELS FORMS OF THE FUNNEL BEAKER CULTURE FROM LOWER SILESIA}

\section{SUMMARY}

The lack of a unified system of description of vessels types of the Funnel Beaker Culture (later called the TRB) in Lower Silesia means that heterogeneous terminology prevents precise classification of ceramic forms found at sites of the culture (cf. e.g. Cholewa 1998, 126, 129; Romanow 1973, 87-89; Wojciechowski 1973, 35-36). In terms of progress on the principles of the morphology analysis of pottery, Lower Silesia lags behind other Polish regions, where a similar problem with the TRB pottery has been clarified since the 1980s, which has led to the development of propositions of the classification based mainly on the metric system, objectivising the identification of the shape of vessels (Jankowska 1980, 31-37, 48-53; Kośko 1981, 23-32, Gumiński 1989, 41n). Anna KulczyckaLeciejewiczowa made the first attempt to create this kind of typology for the artefacts from Lower Silesia in her monograph of the Neolithic settlements from sites in Strachów, Kondratowice district (1997, 178-185). A deficiency of the proposed typology is insufficient description of the subtypes of forms, leaving too much room for subjective interpretation, and the fact that its use in the analysis of the TRB pottery from other sites requires modifications and additions (cf. Kulczycka-Leciejewiczowa 2001, table 2; Kulczycka-Leciejewiczowa, E. Noworyta 2009, table 3, 4; A. Stanisławski, D. Wojnicka 2014, table 5).

The paper presents a proposition of a classification of vessels types of the Funnel Beaker culture developed on the basis of analyses of artefacts from Lower Silesian sites (table 1). The classification of the TRB vessels forms from Kuyavia proposed by Aleksander Kośko (1981, 23-32), served as a starting point. Vessels from Lower Silesian sites were measured in accordance with the scheme of metric indicators proposed there (fig. 1). The data obtained in this way were used to develop the classification of vessels based on typological groups of the "beaker" pottery, created by the aforementioned author. Due to the fact that numerous analysed vessels do not fit into the context of this typology, it became necessary to develop a new, expanded one by adding superior units and developing and modifying the existing ones. When creating this typology, findings were taken into account concerning the forms of vessels proposed for Strachów by A. Kulczycka-Leciejewiczowa, as well as the classification of the materials of the TRB from neighbouring regions such as Upper Silesia (Bukowska-Gedigowa 1975, 87-122; table I-II) and Moravia (Procházková, Šmíd 1999), or clarification of the typology for the early TRB in Kuyavia (S. Rzepecki 2004: 61-64 - beaker type E), as well as the classification of artefacts of the Globular Amphora culture from Kuyavia (Szmyt 1996, 32).

Based on the relationships between metric indicators, 12 major morphological types have been distinguished: beaker $(\mathrm{P})$, mortar beaker $(\mathrm{PM})$, vase $(\mathrm{W})$, bowl (M), pot (G), amphora (A), one-segment amphora (AJ), jug (D), mug (K), collared flask (F), plate (T) and drum (B) (fig. 2-10). The lower-level units are based both on the relations of individual indicators, as well as on secondary micro-morphological qualities (forms of rims, shapes of bodies, etc.). For the clarity of the systematics, each morphological type is denoted by the first or the first two letters of the name, while the subtypes or variants are denoted by consecutive Arabic numerals. Consequently, that leads to denoting a vessel by an integral number, the length of which depends on extensiveness of the description of the form. Such notation allows to extend the typology in the case of discovery of new vessels, the shape of which does not fall within the presented criteria. It also allows, in the case of certain morphological types, that some information regarding a subtype or a variant from a sequence of clarifications, for which we do not have data, can be replaced by the figure 0 (fig. 10: 13). The 
main types, subtypes and variants (with the exception of drums and plates) can be extended with detailed description, denoted by a lower case letter, of the shape of an articulated rim (w), number and points of attachment of handles (u) and the presence of legs (n) (fig. 6). In the case of strongly fragmented vessels, for which precise identification of certain types is difficult, it is possible to use the intermediate category, e.g. W/M in the case of vases and bowls, and, where this possibility exists, to specify the type or subtype, e.g. W/M11.

Adres Autorki:

Mgr Ewa Dreczko

Instytut Archeologii Uniwersytetu Wrocławskiego

ul. Szewska 48

50-139 Wrocław

e-mail: ewa.dreczko@uwr.edu.pl 